\title{
Precursor Lesions of Pancreatic Cancer
}

Suguru Yonezawa, Michiyo Higashi, Norishige Yamada, and Masamichi Goto

Department of Human Pathology, Field of Oncology, Kagoshima University Graduate School of Medical and Dental Sciences, Sakuragaoka, Kagoshima, Japan

This review article describes morphological aspects, gene abnormalities, and mucin expression profiles in precursor lesions such as pancreatic intraepithelial neoplasia (PanIN), intraductal papillary mucinous neoplasm (IPMN), and mucinous cystic neoplasm (MCN) of the pancreas, as well as their relation to pancreatic ductal adenocarcinoma (PDAC). The gene abnormalities in precursors of PDAC are summarized as follows: (1) KRAS mutation and $p 16 / C D K N 2 A$ inactivation are early events whose frequencies increase with the dysplasia grade in both PanIN and IPMN; (2) TP53 mutation and SMAD4/DPC4 inactivation are late events observed in PanIN3 or carcinomatous change of IPMN in both PanIN and IPMN, although the frequency of the TP53 mutation is lower in IPMN than in PDAC; and (3) also in MCN, KRAS mutation is an early event whose frequency increases with the dysplasia grade, whereas TP53 mutation and SMAD4/ DPC4 inactivation are evident only in the carcinoma. The mucin expression profiles in precursors of PDAC are summarized as follows: (1) MUC1 expression increases with the PanIN grade, and is high in PDAC; (2) the expression pattern of MUC2 differs markedly between the major subtypes of IPMN with different malignancy potentials (i.e., IPMN-intestinal type with MUC2+ expression and IPMN-gastric type with MUC2expression); (3) MUC2 is not expressed in any grade of PanINs, which is useful for differentiating PanIN from intestinal-type IPMN; (4) de novo expression of MUC4, which appears to increase with the dysplasia grade; and (5) high de novo expression of MUC5AC in all grades of PanINs, all types of IPMN, MCN, and PDAC. (Gut and Liver 2008;2:137-154)

Key Words: Pancreatic ductal adenocarcinoma; Intraductal papillary mucinous neoplasm; Pancreatic intra- epithelial neoplasia; Mucinous cystic neoplasm; Gene analysis; Mucin expression

\section{INTRODUCTION}

Pancreatic ductal adenocarcinoma (PDAC) is the fourth leading cause of cancer death in USA and the fifth leading cause of cancer death in Japan. ${ }^{1}$ The incidence rate in Japan has been dose to the level with that in Europe or USA, when we compare the age-adjusted incidence rate. The patients with PDAC still shows a poor clinical outcome, in spite of the improvement of the diagnosis and treatment methods. The overall five year survival rate for all patients with or without pancreatectomy after diagnosis is $9.7 \%$ in Japan. On the other hand, the patients with a successful resection of PDACs at the early stage (Stage Ia) have a $39.9 \%$ five year survival rate. ${ }^{1}$ Most of the patients with PDAC, however, are diagnosed in the advanced stages because of the anatomical location of the pancreas, lack of specific symptoms, infiltration to the surrounding organs, or distant metastasis even from a small primary tumor less than $2 \mathrm{~cm}$ in diameter.

For the improvement of the survival of the patients with PDAC, investigation of the precursor lesions is mandatory. Recently, classification of the precursor lesions of pancreatic cancer is well organized, after the establishment of entities of pancreatic intraepithelial neoplasia (PanIN), intraductal papillary mucinous neoplasm (IPMN) and mucinous cystic neoplasm (MCN).

This review article summarises the current status of melecular alterations and mucin expression in the precursor lesions such as PanIN, IPMN and MCN, as well as their relation with PDAC. Most of the data described in

Correspondence to: Suguru Yonezawa

Department of Human Pathology, Field of Oncology, Course of Advanced Therapeutics, Kagoshima University Graduate School of Medical and Dental Sciences, 8-35-1, Sakuragaoka, Kagoshima, 890-8544, Japan

Tel: +81-99-275-5270, Fax: +81-99-265-7235, E-mail: syoneza@m2.kufm.kagoshima-u.ac.jp

Received on August 21, 2008. Accepted on September 23, 2008. 
the present review are summarized in Fig. 1.

\section{MORPHOLOGICAL ASPECTS OF PRECURSOR LESIONS RELATED TO PNACREATIC DUCT ADENOCARCINOMA (PDAC)}

PanIN, IPMN and MCN are well known as precursor lesions related to PDAC.

Adequate and common classification for precancerous lesions in pancreatic ducts is essential for the effective international investigations for the pancreatic carcinogenesis. It is believed that PDACs develop from PanIN, which were previously recognized as pancreatic ductal lesions such as hyperplasia, dysplasia and so on, but were classified into four groups of PanINs: PanIN-1A, PanIN-1B, PanIN-2, and PanIN-3 according to the histological atypia (Fig. 1) after pathology workshop. ${ }^{2}$ For the PanIN lesions, analyses of molecular aspects as well as mucin expression profiles have been performed as describe later.

IPMN is characterized by papillary proliferation of ductal epithelium and production of mucin and usually shows expansive growth, and a favorable prognosis com- pared with PDAC. ${ }^{3-7}$ However, there are several cases showing development of carcinomas derived from IPMNs. In 1999, we classified IPMNs morphologically into three types: villous dark cel type, papillary clear cell type, and compact cell type, in combination of mucin expression profiles. $^{8}$ Later, at an international consensus meeting in 2004, IPMN was classified as four types, gastric type (=papillary clear cell type), intestinal type (=villous dark cel type), pancreatobiliary type, and oncocytic type (=compact cell type, =intraductal oncocytic papillary neoplasm (IOPN) by Adsay et al. ${ }^{9}$, by the morphological findings as well as the specific mucin expression profiles, as described below. ${ }^{10}$ In both of gastric type and intestinal type, benign, borderline, and malignant lesions are recognized, but development of carcinomas derived from IPMN is frequent in the intestinal type, whereas rare in the gastric type. ${ }^{6,7}$ In contrast, the pancreatobiliary type and oncocytic type are usually malignant lesions..$^{10,11}$

MCNs are rare tumor, and are developed exclusively in women. The lesions are usually located in body to tail, and show no communication with the pancreatic ductal system. MCNs show multilocular to unilocular epithelial cysts lined by mucin producing cuboidal to columnar cells

\begin{tabular}{|c|c|c|c|c|c|c|c|c|c|c|}
\hline & Chromosome & Normal & $\begin{array}{c}\text { PanIN } \\
-1 \mathrm{~A}\end{array}$ & $\begin{array}{c}\text { PaniN } \\
-1 \mathrm{~B} \\
\end{array}$ & PanIN-2 & PanlN-3 & PDAC & $\begin{array}{l}\text { IPMN-intestinal } \\
\text { type }\end{array}$ & $\begin{array}{c}\text { IPMN-gastric } \\
\text { type }\end{array}$ & $\mathrm{MCN}$ \\
\hline \multicolumn{11}{|l|}{ Genes } \\
\hline K-ras* & 12p12.1 & $0 \%$ & $55-60 \%$ & 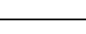 & $>80 \%$ & \multirow{3}{*}{$\begin{array}{l}92 \% \\
-92 \% \\
\end{array}$} & $75-100 \%$ & \multirow[t]{2}{*}{$(38.5-100 \% a$} & \multirow[t]{2}{*}{ ) } & \\
\hline HER2/neu* & $17 q 21.1$ & & $82 \%$ & $86 \%$ & $\longrightarrow$ & & $70 \%$ & & & \\
\hline $\mathrm{p} 16^{\dagger}$ & $9 p 21$ & & $30 \%$ & $55 \%$ & $\longrightarrow$ & & $80-95 \%$ & $78 \% a$ & $0 \% \mathrm{~b}$ & \\
\hline $\mathrm{p} 53^{\dagger}$ & $17 p 13.1$ & & $0 \%$ & $0 \%$ & $0 \%$ & $12 \%$ & $50-75 \%$ & $38-50 \% a$ & $0 \% \mathrm{~b}$ & \\
\hline $\mathrm{Smad} / \mathrm{DPC} 4^{\dagger}$ & $18 q 21.1$ & & $0 \%$ & $0 \%$ & $0 \%$ & $30 \%$ & $55 \%$ & $10-44 \% a$ & & \\
\hline $\mathrm{BRCA}^{\dagger}{ }^{\dagger}$ & $13 q 12-13$ & & $0 \%$ & $0 \%$ & $0 \%$ & & $7-10 \%$ & & & \\
\hline \multicolumn{11}{|l|}{ Mucins } \\
\hline \multirow[t]{2}{*}{ MUC1 } & 1q21 & $33 \%$ & $20 \%$ & $20 \%$ & $44 \%$ & $57 \%$ & $96 \%$ & $0 \%$ & $3 \%$ & $0 \%$ e or $87.5 \% f$ \\
\hline & & $24 \% c$ & $71 \% c$ & $69 \% c$ & $75 \% c$ & $75 \% c$ & $80 \% c$ & & & \\
\hline \multirow[t]{2}{*}{ MUC2 } & $11 \mathrm{p} 15$ & $0 \%$ & $0 \%$ & $0 \%$ & $0 \%$ & $0 \%$ & $0 \%$ & $96 \%$ & $3 \%$ & $0 \% e, f$ \\
\hline & & $0 \% \mathrm{c}$ & $1 \% c$ & $0 \% c$ & $0 \% \mathrm{c}$ & $0 \% c$ & $6 \% c$ & & & \\
\hline MUC3 & $7 q 22$ & $18 \% d$ & $45 \% d$ & $60 \% d$ & $65 \% d$ & $89 \% d$ & $68 \% d$ & & & \\
\hline \multirow[t]{2}{*}{ MUC4 } & $3 q 29$ & $0 \%$ & $14 \%$ & $5 \%$ & $11 \%$ & $14 \%$ & $32 \%$ & & & \\
\hline & & $9 \% d$ & $11 \% d$ & $14 \% d$ & $23 \% d$ & $62 \% d$ & $79 \% d$ & & & \\
\hline \multirow[t]{2}{*}{ MUC5AC } & $11 p 15$ & $0 \%$ & $83 \%$ & $90 \%$ & $100 \%$ & $71 \%$ & $92 \%$ & $92 \%$ & $100 \%$ & $37.5 \% \mathrm{e}$ or $100 \% \mathrm{f}$ \\
\hline & & $2 \% c$ & $69 \% c$ & $89 \% c$ & $91 \% \mathrm{c}$ & $89 \% c$ & $82 \% c$ & & & \\
\hline \multirow[t]{2}{*}{ MUC6 } & $11 p 15.5-p 15.4$ & $67 \%$ & $83 \%$ & $75 \%$ & $72 \%$ & $57 \%$ & $56 \%$ & $37 \%$ & $92 \%$ & $30 \% \mathrm{e}$ \\
\hline & & $29 \% c$ & $74 \% c$ & $67 \% \mathrm{c}$ & $66 \% \mathrm{c}$ & $56 \% c$ & $35 \% \mathrm{c}$ & & & \\
\hline \multicolumn{11}{|l|}{ Carbohydrates } \\
\hline \multicolumn{2}{|l|}{ Sialyl Tn } & $2 \% c$ & $5 \% c$ & $8 \% c$ & $6 \% c$ & $67 \% c$ & $77 \% \mathrm{c}$ & $100 \%$ & & \\
\hline \multicolumn{2}{|l|}{ CD10 } & $67 \%$ & $23 \%$ & $60 \%$ & $17 \%$ & $14 \%$ & $13 \%$ & & & \\
\hline
\end{tabular}

* activation; $\dagger$ loss of function

a, IPMN-carcinoma; b, IPMN-adenoma; c, data in Ref. No. 103; d, data in Ref. No. 101; e, data in Ref. No. 69; f, data in Ref. No. 119.

Fig. 1. Summary of various gene mutations and mucin expression profiles in precursor lesions (PanIN, IPMN, and MCN) and PDAC. Gene mutations are from various sources as described in the text. Expression profiles of mucins are from our data (references 5, 7, 99 and 102) and also from references 69, 101, 103 and 119. Data of sialyl-Tn in PanIN are from reference 103. Data of CD10 are from our data (reference 102). The rates of gene abnormalities in IPMN are described in categories of IPMN carcinoma and IPMN adenoma, respectively ( $a$ and $b$ ). The data of mucin expression in IPMN are described in categories of intestinal- and gastric-type IPMNs, and no data of carcinoma cases are included. 
surrounded by so-called ovarian-like stroma, and are classified as adenoma, borderline, and malignant lesions. ${ }^{3,4}$

\section{GENE ABNORMALITIES IN PRECURSOR LE- SIONS OF PANCREATIC DUCTAL ADENICAR- CINOMA (PDAC)}

\section{Molecular aspects in PDAC and PanIN}

\section{1) Gene mutation in PDAC and PanIN}

a) KRAS mutation in PDAC and PanIN

i) KRAS mutation in PDAC

KRAS is located at chromosome 12p12.1. Since the reports of KRAS at codon 12 mutation in pancreatic cancer by Almoguera et al. ${ }^{12}$ and Smit et al., ${ }^{13}$ there are many reports of KRAS mutation in human PDAC. KRAS mutation is observed exclusively in codon 12 and exceptionally in codons 13 and 61. The other HRAS and NRAS mutations were not reported in human PDAC. KRAS mutation is frequent in PDAC (75-100\%), ${ }^{14}$ compared with in the carcinomas of the other organs such as thyroid (50-60\%), colon (40-60\%), lung (20-40\%), esophagus (rare) and stomach (rare). ${ }^{15}$ On the other hand, KRAS mutation is rare in islet cell tumors or acinic cell carcinomas of the pancreas. ${ }^{16}$ In human PDAC, GGT (Gly) to GAT (Asp) is the main type of mutation in Japanese patients, whereas not only GGT (Gly) to GAT (Asp) but also GGT (Gly) to GTT (Val), CGT (Arg) or TGT (Cys) is reported in US-European patients. ${ }^{15}$

KRAS mutation in PDAC showed no correlation with clinicopathologic factors such as tumor size, stage and outcome and so on, because of so high frequency of KRAS mutation in PDAC. In addition, KRAS mutation is seen also in IPMN and PanIN as described below.

\section{ii) KRAS mutation in PanIN}

Yanagisawa et al. demonstrated, in their early study of mucous cell hyperplasia of pancreas in patients with chronic panceratitis, KRAS mutation at codon 12 were deteced in $62.5 \%$ of the nonatypical mucous cell hyperplasia, ${ }^{17}$ which show the same histological findings as PanIN-1a, PanIN-1b and PanIN-2 noted in the article of PanIN classification, ${ }^{2}$ from the microscopic pictures and description of the histological findings in the article reported by Yanagisawa et al. ${ }^{17}$ At that time, a concept of "mucous cell hyperplasia-adenoma-carcinoma sequence" was considered. When the frequencies of KRAS mutation in ductal hyperplasia lesions were adopted to PanIN system, KRAS mutation is seen in about half of the early non-papillary lesion (PanIN-1A) and in more than $80 \%$ of the papillary lesions (PanIN-1B and the higher grades). ${ }^{18}$ b) HER-2/neu in PDAC and PanIN

HER-2/neu, one of epidermal growth factor receptor (EGFR) family, is located at chromosome 17q21.1, and is over expressed in PDAC. ${ }^{19}$ HER-2/neu is not expressed in the lining epithelium of normal pancreatic duct, but is highly expressed in PanIN (PanIN-1A: 82\%, PanIN-1B: $86 \%$, PanIN-2 and the higher grades: $92 \%) .{ }^{19}$

c) $p 16 / C D K N 2 A$ mutation in PDAC and PanIN

p16/CDKN2A is located at chromosome 9q21. PDAC shows high frequency (80-95\%) of the abnormal loss of p16 gene product. ${ }^{20}$ Abnormal loss of $p 16 / C D K N 2 A$ gene product is seen somewhat later than KRAS mutation and the frequencies are increased according to the progression of the grades of PanIN (PanIN-1A: 30\%, PanIN-1B: 55\%, PanIN-2 and the higher grades: $92 \%){ }^{21}$

d) TP53 mutation in PDAC and PanIN

TP53 is located at chromosome 17p13.1. In immunohisochemistry (IHC), PDAC shows high frequency (50$75 \%$ ) of TP53 product which means abnormality of TP53. ${ }^{14}$ In PanIN, TP53 product is not recognized in the lower grade of PanIN-1 up to PanIN-2, but is observed in $12 \%$ of PanIN-3 (CIS). ${ }^{22}$

e) SMAD4/DPC4 mutation in PDAC and PanIN

SMAD4/DPC4, tumor suppressor gene (detected in pancreatic carcinoma, locus 4) was isolated at a locus $18 \mathrm{q} 21.1$ of chromosome which was frequently lost in PDAC. $^{23}$ In IHC, inactivation of SMAD4/DPC4 is seen in $55 \%$ of PDAC. ${ }^{24}$ In PanIN, expression loss of SMAD4/ DPC4 product is not recognized in the lower grades of PanIN up tp PanIN-2, but is observed in about $30 \%$ of PanIN-3 (CIS) ${ }^{25}$ Expression findings of SMAD4/DPC4 in PanIN may predict the progression of PanIN to PDAC. ${ }^{26}$

f) BRCA2 mutation in PDAC and PanIN

$B R C A 2$, which was isolated at a locus $13 \mathrm{q}$ of chromosome, is inactivated in 7 to $10 \%$ of PDAC. The allelic loss is seen in highly atypical lesion such as PanIN-3, but the normal allales are preserved in low dysplastic lesions. ${ }^{27}$ Thus, the BRCA2 mutation is considered to be a rate event of the pancreatic carcinogenesis, like p53 and DPC4.

\section{2) Loss of heterozygosity (LOH) in PDAC and PanIN}

According to the detailed study using microdissection by Yamano et al., frequencies of $\mathrm{LOH}$ in [normal epithelium, non-papillary hyperplasia like PanIN-1, papillay hyperplasia like PanIN-2, severe ductal hyperplasia like PanIN-3, and PDAC] were as follows; [0\%, 11\%, 17\%, 90\%, and $100 \%$ at $9 \mathrm{p}],[0 \%, 0 \%, 0 \%, 80 \%$, and $80 \%$ at $17 \mathrm{p}]$ and $[0 \%$, $0 \%, 0 \%, 88 \%$, and $88 \%$ at $18 \mathrm{q}],[0 \%, 0 \%, 0 \%, 63 \%$, and $50 \%$ at $6 \mathrm{q}]$, respectively. ${ }^{28}$ Namely, PanIN-1 and PanIN-2 showed LOH only at 9p, but not at 17p, 18q, nor at 13q. 
In contrast, PanIN-3 and PDAC showed LOH at 9p, 17p, $18 \mathrm{q}$ and 13q. These findings are well consistent with the above mentioned abnormal gene mutation, i.e., p16 mutation occurred at chromosome $9 p$ is seen at the early event of dysplastic change such as PanIN-1 and PanIN-2, whereas TP53 mutation at $17 \mathrm{p}$ and SMAD4/DPC4 mutation at $18 \mathrm{q}$, and BRCA2 mutation at $13 \mathrm{q}$ are seen at the late event of dysplastic change such as PanIN-3.

The other study for $\mathrm{LOH}$ demonstrated that important cancer suppressor genes are located at 1p, 6q, 9p, 12q, $17 \mathrm{p}$ and $18 \mathrm{q},{ }^{29}$ which include $9 \mathrm{p}, 17 \mathrm{p}$ and $18 \mathrm{q}$ mentioned above. $^{28} \mathrm{LOH}$ at $12 \mathrm{q}, 17 \mathrm{p}$ and $18 \mathrm{q}$ is related with poor prognosis, whereas $\mathrm{LOH}$ at $9 \mathrm{q}$ is not related with poor prognosis. ${ }^{30}$ These findings are also consistent with that $S M A D 4 / D P C 4$ mutation at $18 \mathrm{q}$ are seen in the late event such as PanIN-3 and PDAC, but $p 16 / C D K N 2 A$ inactivation is seen in the early event such as PanIN-1.
3) Analysis by comparative genomic hybridization (CGH) or fluorescence in situ hybridization (FISH) in PDAC and PanIN

$\mathrm{CGH}$ and FISH, which are different methods from LOH, can analyze changes of genomic copy number. CGH can analyze all the areas of genome, whereas FISH can analyze the details of genomic change in particular areas of gene. A CGH study disclosed loss of 3p, 6q, 9p, 18q and 21q, and amplification of 7p, 7q, 8q, 11q, 20p and 20q in PDAC, by Fukushige et al. ${ }^{31}$ Also in this CGH method, 9p and $18 \mathrm{q}$ are included in genomic loss area. They also demonstrated by the analyses of $\mathrm{CGH}$ and $\mathrm{LOH}$ of cells in pancreatic juice that loss of chromosome 18q is an early event of carcinogenesis of PDAC, but no genomic abnormality in the patients with chronic pancreatitis. ${ }^{32}$

\section{4) Epigenetics in PDAC and PanIN}

Methylation of $\mathrm{CpG}$ islands at gene promotor area (Fig. 2) seems to be one of the mechanisma of gene silencing

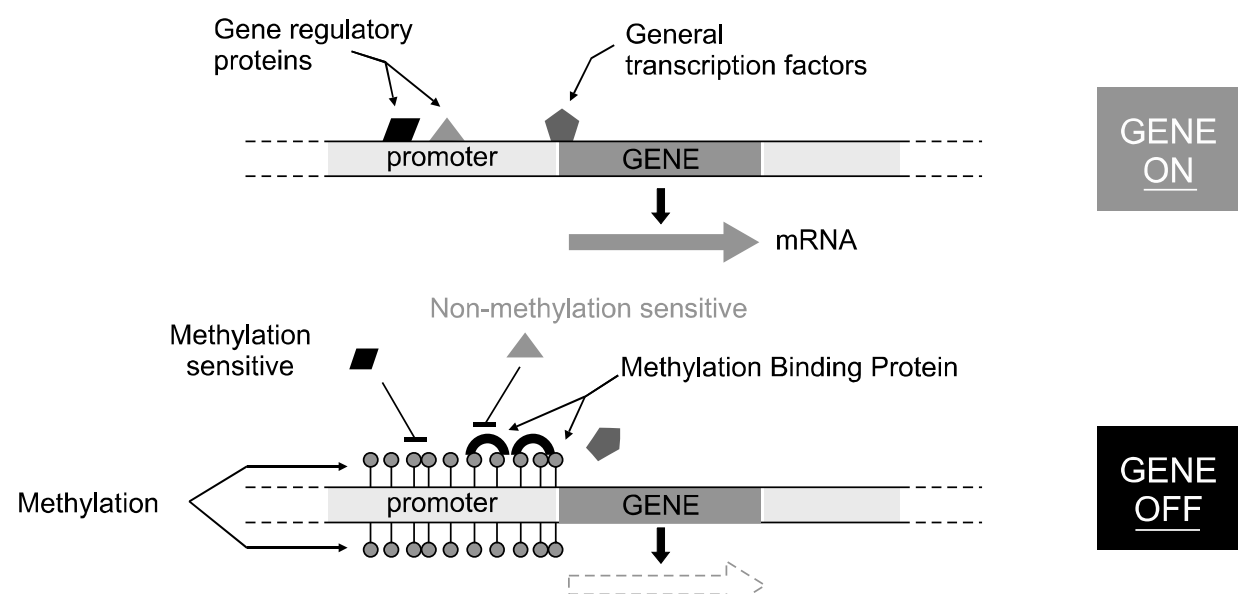

Fig. 2. Mechanism of DNA methylation related to gene silencing.

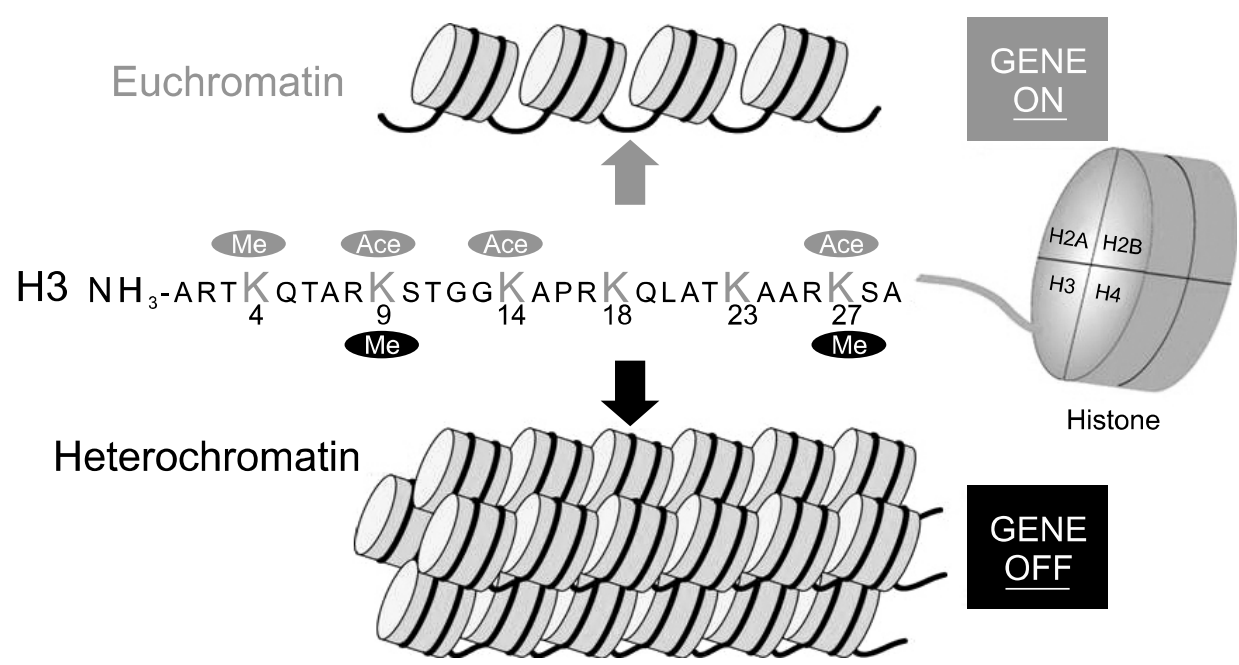

Fig. 3. Mechanism of histone modification related to gene silencing. 
in PDACs. ${ }^{33}$ The gene silencing by methylation in PDACs show various rates from high (over 90\%) such as UCHL1, NPTX2, SARP2, ppENK and CLDN5, to low (under 10\%) such as E-CAD, THBS1, MLH1, CYCLLIN $G$ and DAP kinase. ${ }^{33-36}$ Particularly, Fukushima et al. demonstrated that methylation of promoter CpG of ppENK is not observed in normal pancreatic tissue, but its frequencies increase along with PanIN grades, and shows very high rate (over 90\%) in PDAC. ${ }^{37}$ As the methylation of ppENK is well preserved in pancreatic juice, it may be optimal for a diagnostic marker of PDAC. ${ }^{38}$ Sato et al. showed that, at least, one of the highly methylated genes such as NPTX2, SARP2, CLDN5 and so on described above is observed in $100 \%$ of the primary lesions of PDACs, and is also found in $75 \%$ of the pancreatic juice from the patients with PDAC. $^{34}$

The methylation of the promoter region of the genes is related with gene silencing, whereas non- or hypo-methylation may lead to gene upregulation. Actually, our recent study, in relation with mucin expression in cancer cell lines including PDAC cells, disclosed for the first time that MUC1 gene expression, which is apparently related with poor prognosis of pancreatic tumors, is regulated by epigenetic mechanisms including DNA methylation (Fig. 2) and histone modification (Fig. 3) at the promoter area, which was confirmed by the treatment using DNA methylation inhibitor (5-aza-2'-deoxycytidine) and histone deactylase inhibitor (trichostatin A) (Fig. 4). ${ }^{39}$ Before the demonstration of epigenetic regulation of MUC1 gene expression, we had also reported the details of epigenetic regulation mechanism of MUC2 gene expression. ${ }^{40,41}$

\section{5) Clinical application of molecular profiling in PDACs}

Logsdon et al. performed screening of more than 6,800 genes by molecular profiling in PDACs, chronic pancreatitis, normal pancreatic tissue and pancreatic cancer cell lines, and listed 158 genes specific to PDAC, and then successfully could choose 80 genes showing more than 3 times overexpression in PDACs compared with chronic pancreatitis. They also identified four proteins (14-3-3- $\sigma$, S100P, S100A6, $\beta 4$ intergrin) coded by the genes specific to PDAC, and have a plan to apply them as a effective marker for PDAC. ${ }^{42}$

\section{Molecular aspects in IPMN}

\section{1) Gene mutation in IPMN}

In DNA ploidy, most benign IPMNs are diploid, whereas malignant IPMNs show a tendency of aneuploid. ${ }^{43}$ Various genetic changes have been reported in IPMNs, but the frequencies are lower compared with invasive PDAC as follows.

\section{a) KRAS mutation in IPMN}

The frequencies of KRAS mutations in IPMNs show varieties of the ranges from low rate $(38.5 \%)^{44}$ to high rate $(100 \%)^{45}$ even within the cases of IPMN-carcinoma in many literatures, most of which reported a lower frequency compared with that reported in PDAC. ${ }^{14}$ The KRAS mutations are detected in IPMN from the benign to malignant conditions. Although the mutations were observed even in IPMNs without dysplasia, the frequency increases along with the increasing grade of dysplasia. ${ }^{46,47}$

b) $p 16 / C D K N 2 A$ and TP53 mutations in IPMN

The frequency of $p 16 / C D K N 2 A$ mutation in IPMNs varies in several reports; $p 16 / C D K N 2 A$ gene inactivation is not detected in one report investigating IPMN adenoma $(0 \%)^{48}$ but high in another report studying IPMN carcinoma $(78 \%){ }^{49}$ There are two studies reporting that p16/CDKN2A inactivation increases along with dysplasia significancy. ${ }^{50,51}$

The frequency of TP53 mutations in IPMNs reported in literatures show wide range from $0 \%$ in IPMN-hyperplasia or adenoma (whereas $38 \%$ in IPMN-carcinoma) ${ }^{52}$ to $50 \%,{ }^{53}$ although the latter report did not note the dysplasia grading of IPMN. Since TP53 mutation is usually seen

* 5-Aza-2'-deoxycytidine (5-AzadC): DNA methylation inhibitor

* Trichostatin A (TSA): histone deacetylase inhibitor

MUC1 negative
cell lines
(no treat)

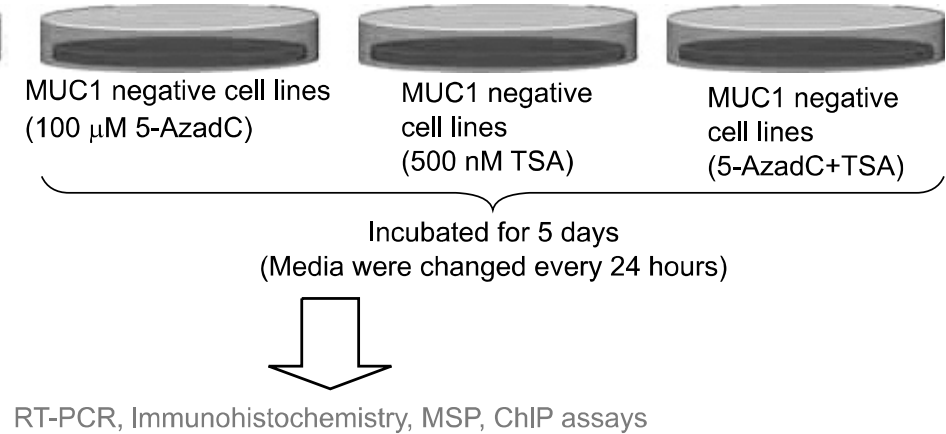

Fig. 4. Confirmation of epigenetic silencing of the MUC1 gene by a methylation inhibitor (5-aza2'-deoxycytidine) and a histone deacetylase inhibitor (trichostatin A). 
in IPMNs with significant dysplasia, the mutation is considered to be a late event in IPMN lesions.

c) SMAD4/DPC4 mutation in IPMN

Inactivation of SMAD4/DPC4 is rare in IPMNs, i.e., most IPMNs-intestinal type express Dpc4 protein at non-invasive stage. ${ }^{48,50,51,54}$ It is noteworthy that invasive carcinomas (frequently mucinous carcinoma) derived from IPMNs-intestinal type loss of Dpc4 protein expression in about $10 \%,^{50,54}$ whereas the frequency of loss of Dpc4 protein expression in PanIN3 is $30 \%$, and it in PDAC without IPMN is $55 \% .^{23-25}$ Thus, loss of Dpc4 protein expression seems to be more specific in PDAC as well as in PanIN3 than in IPMN-intestinal type.

d) $S K T 11 / L K B 1$ and APC mutation as well as wntsignaling pathway abnormality in IPMN

Biallelic somatic mutation of SKT11/LKB1 (Peutz-Jeghers gene) has been reported in IPMN in patients with Peutz-Jeghers syndrome, ${ }^{55}$ and it is observed also in $1 / 4$ of sporadic IPMNs. ${ }^{56}$ Allelic loss of the wild type APC has been also reported in IPMN in patients with familial adenomatous polyposis. ${ }^{57}$ The wnt-signaling pathway also showed abnormalities in sporadic IPMNs. ${ }^{58}$

\section{2) Loss of heterozygosity (LOH) in IPMN}

LOH in IPMN is shown in chromosomes 9p, 6q, 17p, and $18 \mathrm{q}$, which may be related with inactivation of the p16/CDKN2A gene on 9p, TP53 gene on 17p, and SMAD/DPC4 on $18 \mathrm{q} .{ }^{49,59}$

\section{3) Epigenetics in IPMN}

Aberrant hypermethylation is shown in most IPMNs in at least one gene, and is associated with loss of gene expression such as $p 16 / C D K N 2 A$ and $p p E N K .^{60}$ Increase of the number of hypermethylated loci is related with increasing grade of dysplasia in IPMN. ${ }^{60-62}$

\section{4) Other gene abnormalities including mucin gene in IPMN}

IPMNs show overexpression of genes in gastric mucosa such as MUC5AC, pepsinogen $C$, claudin 18 and cathepsin $E .^{63,64}$ Trefoil factor gene (TFF gene) is also upregulated in IPMN. ${ }^{64}$ In TFF genes, TFF1 and TFF2 are expressed in normal gastric epithelium, and TFF3 in intestinal epithelium. As noted later, there are tow major subtypes in IPMN, intestinal type and gastric type. Thus, it is an interesting area of future study to make clear whether those genes related with gastric mucosa or intestinal mucosa are related exclusively with IPMN-gastric type or IPMN-intestinal type respectively.

\section{Molecular aspects in MCN}

\section{1) Gene mutation in $M C N$}

Also in MCNs, molecular abnormalities are accumulated in the progression of dysplasia. ${ }^{43,65}$ Most benign MCNs are diploid, whereas malignant MCNs sometimes show aneuploid. ${ }^{66}$ The clonality of the epithelium in $\mathrm{MCNs}$ is related with the inactivation of the X-linked phosphoglycerate kinase gene, ${ }^{46}$ which may be related with MCN development exclusively in women.

a) KRAS, TP53, SMAD/DPC4 genes mutation in MCN KRAS mutation at codon 12 is observed as the early event and increase the frequency according to the degree of dysplasia, on the other hand, TP53 mutation is a relative late event in in situ or invasive mucinous cystadenomacarcinomas. ${ }^{43,65,67-70}$ Inactivation of SMAD/DPC4 gene is also a late event, and about half of invasive mucinous cystadenomacarcinomas show loss of Dpc4 expression, while benign MCNs show no loss of Dpc4 expression. ${ }^{69,71}$ It is very interesting that the ovarian-type stromal cells show no loss of Dpc4 indicating non-neoplastic characteristics of the stromal cells. ${ }^{71}$

\section{Conclusion of gene abnormalities in precursor lesions of PDAC}

In conclusion, the gene abnormalities in precursors of PDAC are summarized as follows, (1) KRAS mutation and $p 16 / C D K N 2 A$ inactivation are early events in the progression of the precursors of PDAC and show increase of the frequencies along with dysplasia grade in both PanIN and IPMN; (2) TP53 mutation and SMAD4/DPC4 inactivation are late events observed in PanIN3 or carcinomatous change of IPMN in both PanIN and IPMN, although the frequency of TP53 mutation in IPMN is low compared with that in PDAC; (3) Also in MCN, KRAS mutation is an early event and increases the frequency along with dysplasia grade, whereas TP53 mutations is seen in carcinoma in situ and invasive carcinoma, and SMAD4/DPC4 inactivation is noted only in invasive carcinoma.

\section{MUCIN EXPRESSION IN PRECURSOR LESIONS OF PANCREATIC DUCTAL ADENICARCINOMA (PDAC)}

\section{Overview of mucin}

Mucins are high molecular weight glycoproteins with oligosaccharides attached to serine or threonine residues of the mucin core protein backbone by O-glycosidic linkages, which are produced by various epithelial cells. Core 


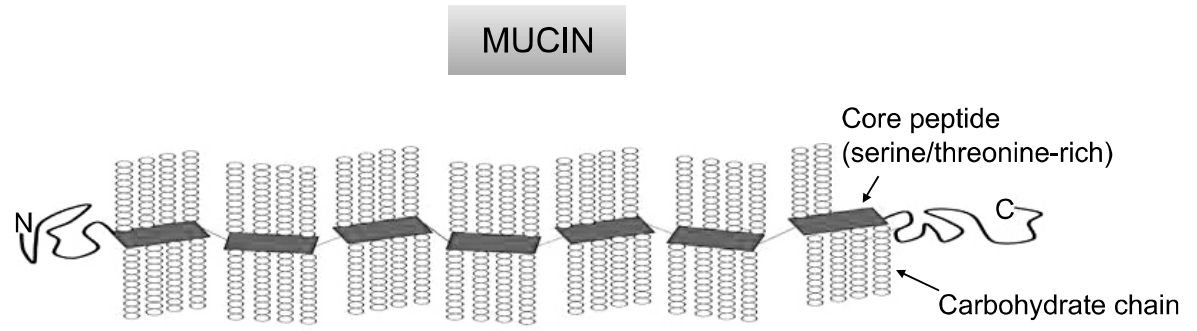

MUC1, MUC3, MUC4 (membrane-associated mucin)

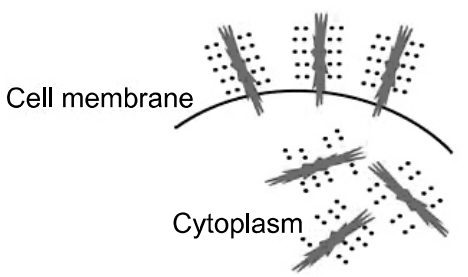

MUC2, MUC5AC, MUC6 (secreted mucin)

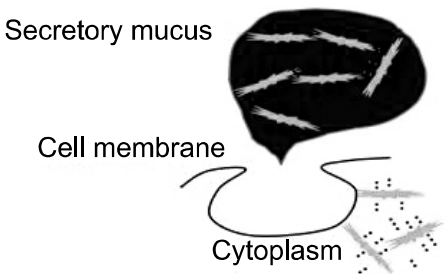

Fig. 5. Basic structure of mucin, and categories of membraneassociated mucin and secreted mucin. proteins for human mucins (MUC1-MUC9, MUC11-13, MUC15-20) have been identified during these two dicades. ${ }^{72-76}$ Mucins are categorized into: membrane- associated mucins (MUC1, MUC3 MUC4, MUC12, MUC16 and MUC17) and secreted mucins (MUC2, MUC5AC, MUC5B, MUC6 and MUC7) (Fig. 5). ${ }^{72,76}$

Our series of IHC studies for mucin expression in various human tumors, including pancreatic tumors, have demonstrated that the expression of MUC1 mucin (membrane mucin) is related to invasive proliferation of tumors and/or a poor outcome for patients..$^{5-7,77-88}$ On the other hand, the expression of MUC2 mucin (intestinal type secretory mucin) is related to non-invasive proliferation of tumors and/or a favorable outcome for patients. ${ }^{5-7,77,78,81-83,87-91}$

In this review article, we demonstrate expression of several mucins, i.e., MUC1 (pan-epithelial membrane mucin), MUC2 (intestinal type secretory mucin), MUC5AC (gastric surface mucous epithelial mucin), and MUC6 (gastric pyloric glandular mucin) in normal tissue, tumors and the precursor lesions of pancreas. Distribution of mucins in normal pancreatic tissue is demonstrated at first. It is followed by expression profile of mucins in PDACs and IPMNs. We describe our recent study of expression of MUC4 (respiratory epithelial mucin) expression in PDACs. Expression profiles of mucins in PanINs and MCNs are also reviewed.

\section{Distribution of mucins in normal pancreatic tis- sue}

In MUC1, various glycoforms of MUC1, from poorly-glycosylated form to fully-glycosylated form, are known

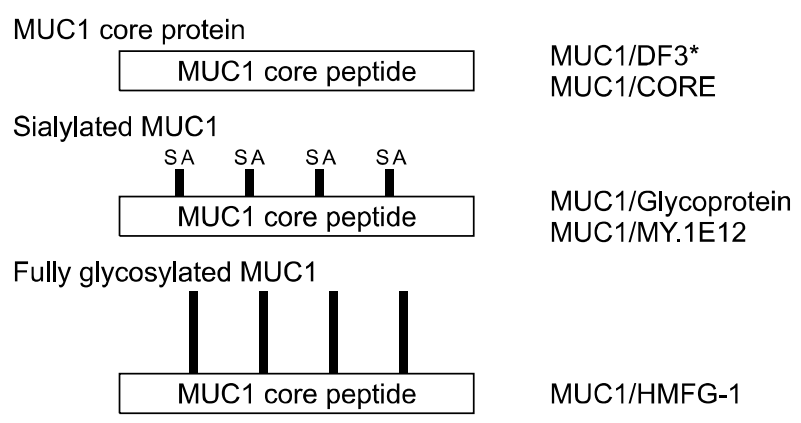

Fig. 6. Different glycoforms of MUC1 and specific antibodies. MUC1 glycoform (left) is recognized by various antibodies (right). ${ }^{*} \mathrm{MUC1} / \mathrm{DF} 3$ basically react with core peptide, but sialic acid (SA) modification might enhance the affinity [Siddiqui J et al., Proc Natl Acad Sci USA 1988;85:2320-2323].

to exist (Fig. 6). These variations can be detected by IHC using epitope-specific monoclonal antibodies. For the simple representation, "MUC1/CORE, MUC1/DF3, MUC1/ MY.1E12, and MUC1/HMFG-1" were used for the MUC1 mucin antigens detected by the monoclonal antibodies (MAbs). Expression of each MUC1 in the normal pancreatic tissue was summarized in Fig. 7. Generally, every MUC1 was expressed in the cell apices of the centroacinar cells, intercalated ducts, intralobular ducts, and focally in the interlobular ducts, but not expressed in the main pancreatic ducts, acini nor islets. ${ }^{7}$ MUC2 and MUC5AC were never expressed in the normal pancreatic tissue. ${ }^{7}$ MUC6 was expressed in the acini in some cases but not in the other cases, although the reason of the discrepancy is unknown (unpublished data). 


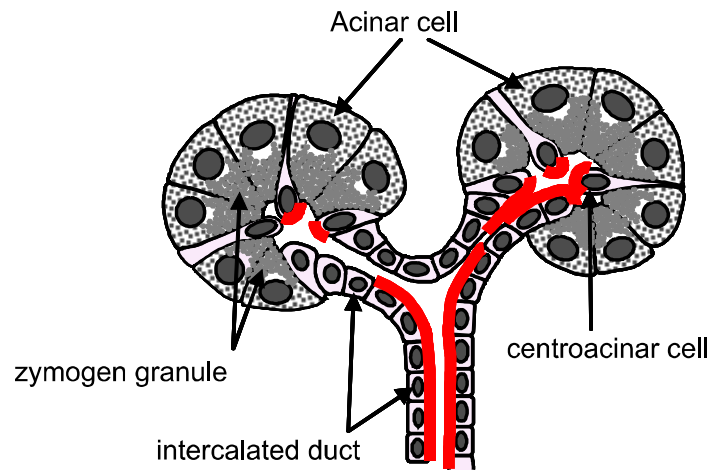

MUC1/CORE and MUC1/DF3

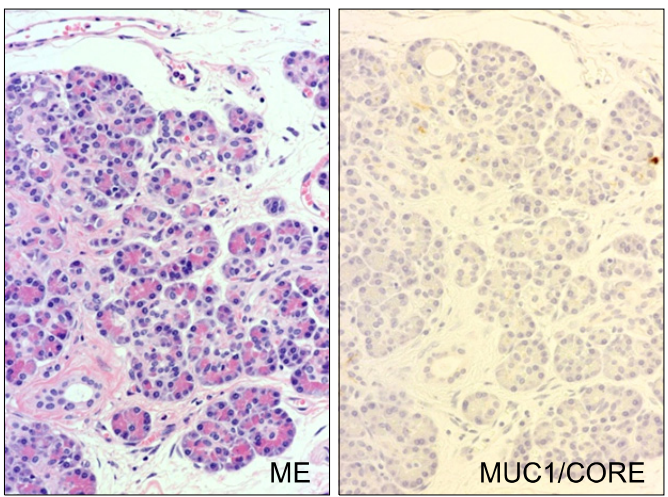

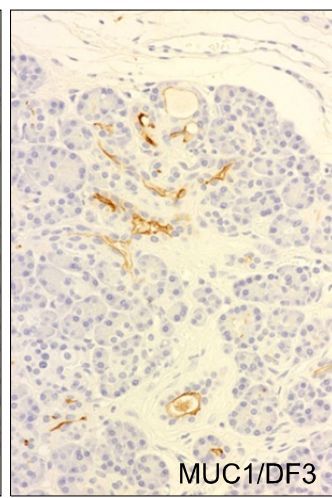

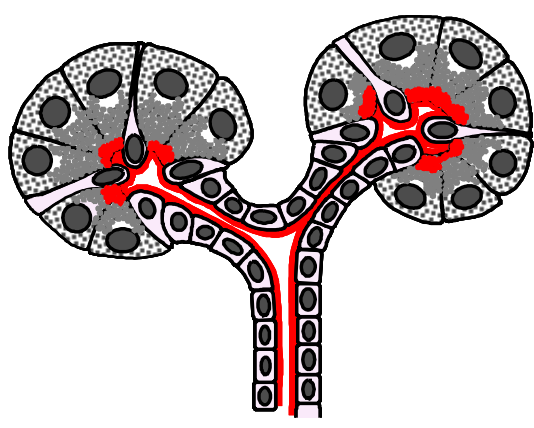

MUC1/MY.1E12 and MUC1/HMFG-1

Fig. 7. Scheme (upper side) and microscopic findings (lower side) of distribution of different glycoforms of MUC1 at acinar to intercalated duct area in normal pancreas. Poorly-glycosylated MUC1 (MUC1/CORE and MUC1/DF3) is expressed in intercalated duct and centroacinar cells (MUC1/CORE usually shows weak staining), whereas glycosylated MUC1 (MUC1/MY1E.12 and MUC1/HMFG-1) is expressed in the wider area including the luminal surface and zymogen granules of acinar cells (Original magnification of the microscopic images: $\times 70$ ).

\section{Internal positive control for mucin expression in pancreatic neoplastic lesions, and Interpretation of immunohistochmistry findings}

MUC1 expression in the centroacinar cells or small ductal system in the non-neoplastic tissue around pancreatic neoplastic lesions is useful for the internal positive control. MUC2 expression in the perinuclear region of the goblet cells of normal intestinal mucosa, MUC5AC expression in the surface mucous cells in the normal gastric mucosa, and MUC6 expression in the cytoplasm of the normal gastric pyloric glands serve as the positive control for their expression. MUC6 expression is observed in the periductal glands in the normal pancreatic tissue, and serve as the internal positive control.

We usually interpretated the IHC stainings for mucins in the lesions as: "negative", under $5 \%$ of neoplastic cells are stained; "focally positive", more than $5 \%$ to under $50 \%$ of neoplastic cells are stained; "apparently positive", more than $50 \%$ of neoplastic cells are stained.

\section{Mucin expression in PDAC and PanIN}

\section{1) Mucin expression in PDAC}

a) Mucin type carbohydrate antigen

Before the serial studies for the expression of mucin core proteins in PDACs, we performed several studies for expression of mucin type carbohydrates in PDACs and IPMNs. Our investigations for the terminal carbohydrate chains demonstrated several impressive results in the carcinomas of gastrointestinal tract and lung, ${ }^{92-94}$ but could not disclose any positive data in pancreatic neoplasms. On the other hand, we could show a high expression of sialyl-Tn (STn), ${ }^{5}$ which is an aberrant form of core region carbohydrate chain, in PDACs and IPMNs (Fig. 8) as well as in the other various adenocarcinomas, whereas STn is seldom seen in the normal tissues. ${ }^{95}$

b) Mucin core protein

i) Preface: distinct difference of MUC1 and MUC2 between PDAC and IPMN

In the early 90's, Yonezawa et al. in the laboratory of 
Dr. Young S. Kim demonstrated a very clear contrast of MUC1 and MUC2 expression in breast and pancreatic cancer cells lines vs. colon cancer cells lines. ${ }^{96}$ After that, we began to research expression of mucin core protines in pancreatic neoplasms, and could demonstrate for the first time a very clear contrast of MUC1 and MUC2 expression between PDAC with invasive growth and poor

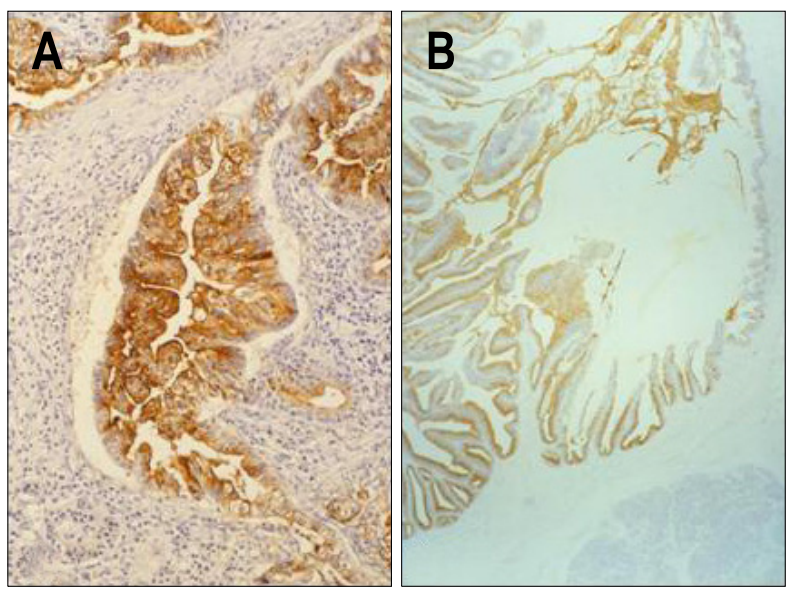

Fig. 8. Expression of sialyl-Tn, an aberrant form of the core-region carbohydrate chain, in PDAC (A) and IPMN (B) (Original magnification of microscopy images: $\mathrm{A}, \times 130$; $\mathrm{B}$, $\times 30)$. prognosis and IPMN with expansive growth and favorable prognosis (Fig. 9); MUC1 is expressed in almost all PDACs, but not in IPMNs, whereas MUC2 is not expressed in PDAC but positive in IPMNs (Fig. 9). ${ }^{5} \mathrm{We}$ also found that the IPMNs with MUC1 negative and MUC2 positive expression is an "intestinal type (Yonezawa's dark cell type $\left.{ }^{8,11}\right) "$, as described precisely later.

ii) Expression of MUC1, including various glycoforms

In our first report of the MUC1 expression in PDACs, we used only MAb FD3 to detect MUC1. ${ }^{5}$ After that, various glycoforms of MUC1 were shown. For glycosylation status of MUC1 mucins in carcinoma tissue, a previous study stressed that MUC1 expressed in breast carcinomas is poorly glycosylated in the MUC1 mucin, whereas normal breast tissue shows little or no expression of the MUC1 mucin core peptide. ${ }^{97}$ This phenomenon is explained in part by the finding that MUC1 core peptide epitopes are masked by carbohydrate side chains produced by normal breast epithelial cells, whereas the carbohydrate side chains of MUC1 produced by breast adenocarcinomas are shorter or less densely distributed than those produced by normal cells. However, our recent study disclosed that sialylated or fully glycosylated MUC1 mucins as well as poorly glycosylated MUC1 mucins were
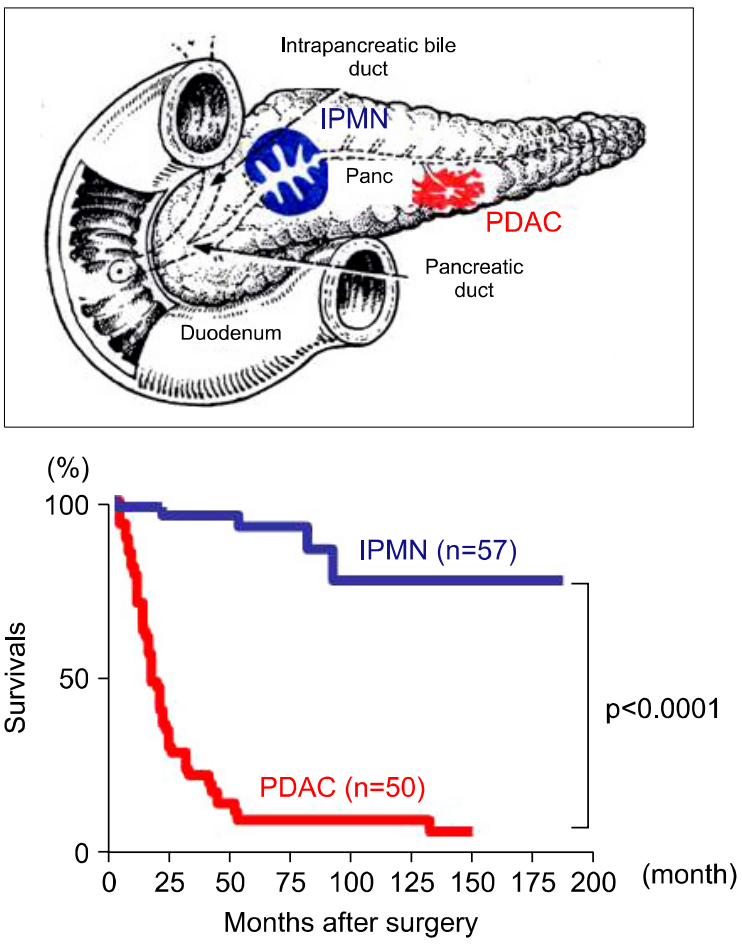
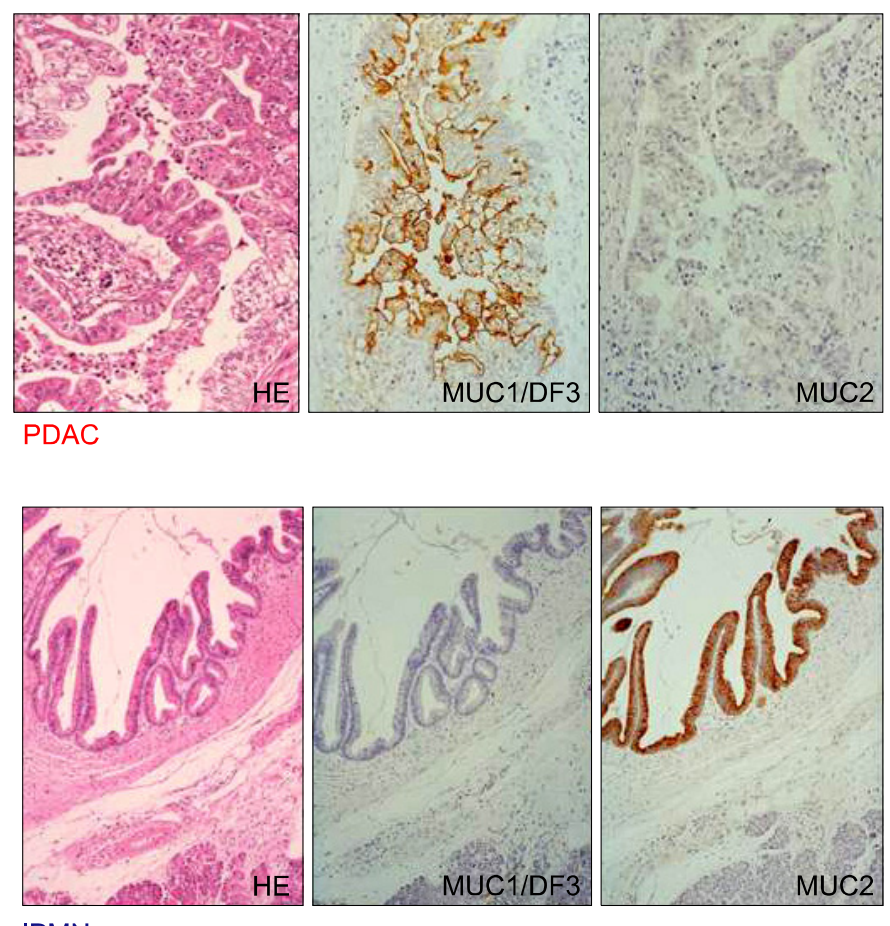

IPMN

Fig. 9. MUC1 and MUC2 expression differed markedly between PDAC with invasive growth and poor prognosis and IPMN with expansive growth and favorable prognosis. MUC1/DF3 is expressed in PDAC but not in IPMN, whereas MUC2 is expressed in IPMN but not in PDAC) (Original magnification of microscopy images: PDAC, $\times 80$; IPMN, $\times 30$ ). 
expressed in breast carcinomas. ${ }^{91}$ Expression of various glycoforms of MUC1 mucins was recognized also in the other human carcinomas of the stomach, ${ }^{78}$ intrahepatic bile duct, ${ }^{81}$ and extrahepatic bile duct. ${ }^{82}$ Nakamori et al. also reported that colorectal carcinomas show a high level expression of fully glycosylated MUC1 mucin in the advanced stages or in the metastatic lesions. ${ }^{98}$

We examined details of expression of different glycoforms of MUC1 in 50 PDACs. ${ }^{7}$ PDACs showed high expression rates of every MUC1 (MUC1/CORE, 66\%; MUC1/DF3, 96\%; MUC1/MY.1E12, 98\%; MUC1/HMFG-1, $76 \%$ ) (Table 1). The expression of MUC1 in PDACs was frequently observed at the lateral and/or basal membrane and in the cytoplasm as well as at the cell apices along the luminal side of the tubular structures, particularly in poorly differentiated PDACs (Fig. 10). It is quite different with the MUC1 expression in the normal pancreas, in

Table 1. Expression Profiles of Mucins in PDAC and IPMN

\begin{tabular}{lccc}
\hline & $\begin{array}{c}\text { PDAC } \\
(\mathrm{n}=50)\end{array}$ & $\begin{array}{c}\text { IPMN-IN } \\
(\mathrm{n}=27)\end{array}$ & $\begin{array}{c}\text { IPMN-GA } \\
(\mathrm{n}=36)\end{array}$ \\
\hline MUC1/CORE & ++ & - & $+/-$ \\
MUC1/DF3 & +++ & - & $-/+$ \\
MUC1/MY.1E12 & +++ & - & + \\
MUC1/HMFG-1 & ++ & $-/+$ & ++ \\
MUC2 & - & +++ & $-/+$ \\
MUC5AC & +++ & +++ & +++ \\
MUC6 & ++ & + & +++ \\
\hline
\end{tabular}

PDAC, pancreatric ductal adenocarcinoma; IPMN-IN, IPMNintestinal type; IPMN-GA, IPMN-gastric type;,$- 0 \% ;-/+$, $0-5 \%$; $+/-, 5-10 \%$;,$+ 10-50 \%$;,$++ 50-90 \%$; +++ , more than $90 \%$.

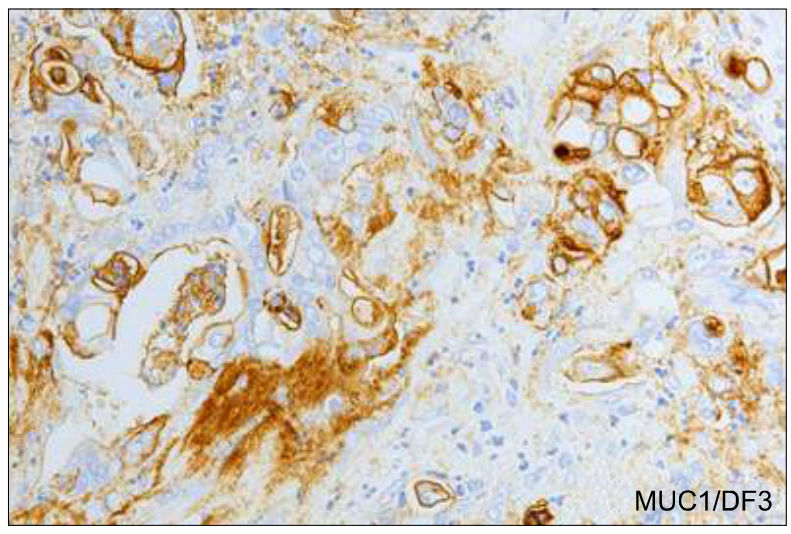

Fig. 10. Expression of MUCl in PDAC was frequently observed at the lateral and/or basal membrane and in the cytoplasm as well as at the cell apices along the luminal side of the tubular structures, particularly in poorly differentiated PDAC (Original magnification of microscopy image: $\times 250$ ). which MUC1 is expressed only at the cell apices of the centroacinar cells and small-sized ducts, as described above (Fig. 7). ${ }^{7}$

iii) Expression of MUC2, MUC4, MUC5AC and MUC6

No expression of MUC2 in PDACs, that we for the first time reported in our previous report, ${ }^{5}$ was confirmed also in our later larger scale study (Table 1$)^{7}$

MUC4 was expressed in 43 (32\%) of 135 PDACs in our another larger scale study (Fig. 11). ${ }^{99}$ In contrast, Swartz et al. and Park et al. reported that MUC4 was expressed in $89 \%$ or in $79 \%$ of IDCs, respectively. ${ }^{100,101} \mathrm{We}$ and both research groups used the same antibody and staining method, but the cut off for the positive expression of MUC4 in our study was $5 \%$ of the neoplastic cells, whereas it in their studies was $1 \%$. Nevertheless, there was a very big difference in the MUC4 expression between our data and their data.

MUC5AC showed very high expression (92\%) in PDACs in our study (Table 1), ${ }^{7}$ like in another report. ${ }^{69}$

MUC6 was expressed in more than half cases $(56 \%)$ (Table 1). ${ }^{7}$

\section{2) Mucin expression in PanIN}

In our study for mucin expression in PanINs, surgically resected 18 lesions of pancreas (3 specimens with chronic pancreatitis, 10 specimens with intraductal papillary-mucinous adenoma, and 5 specimens with IDCs) were collected. $^{102}$ We selected 9 normal ducts, 80 PanINs (PanIN-1A, 35; PanIN-1B, 20; PanIN-2, 18; PanIN-3, 7), and 8 IDCs, and examined expression profiles of mucins
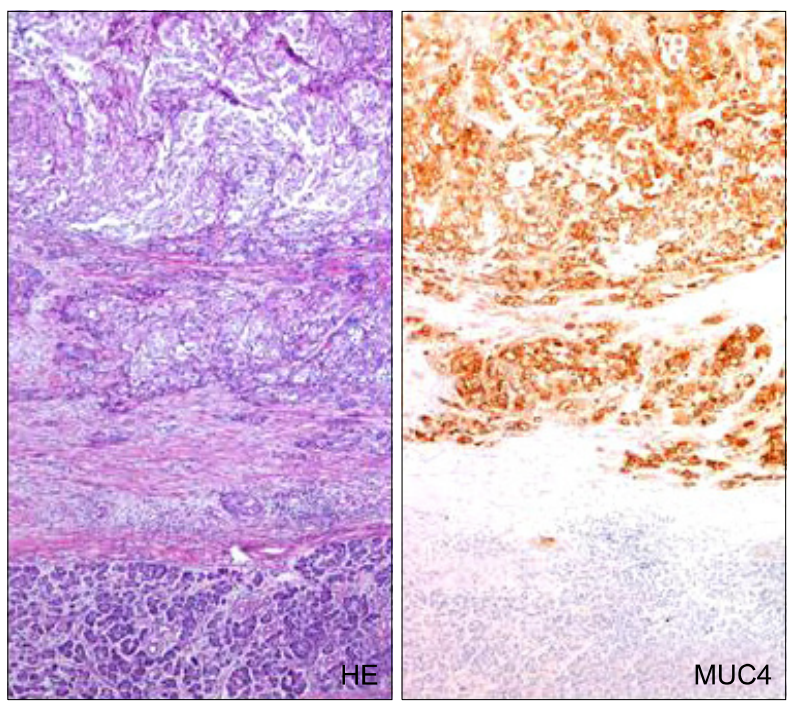

Fig. 11. MUC4 is expressed in PDAC (upper side) but not in the nonneoplastic pancreas (lower side) (Original magnification of microscopy images: $\times 55$ ). 
in them using IHC. As shown in Fig. 1, expression profiles of mucins in all grades of PanINs and PDACs were summarized as follows: (1) Increase in the MUC1 expression correlated with the grades of PanINs. (2) No expression of MUC2 in any grades of PanINs. (3) De novo expression of MUC4 and MUC5AC. ${ }^{102}$

Over expression of MUC1 and no or rare expression of MUC2 in PanINs seem to be a consensus phenomenon among the study groups. ${ }^{102,103}$

Swartz et al. and Park et al. reported that MUC4 expression increases progressively in PanINs. ${ }^{100,101}$ In their studies, as described above, MUC4 expression rates in PDACs were very high. In our study, however, MUC4 expression rates in PDACs was one third of the cases examined. ${ }^{99}$ Thus, we could not detect the progressive increase of MUC4 expression in PanINs. However, the phenomenon of de novo expression of MUC4 in PanINs shows no discrepancy between our study and the studies by Swartz et al. or Park et al. ${ }^{100,101}$

MUC5AC and MUC6 expression is an early event in PanINs in our study ${ }^{102}$ as well as in another study. ${ }^{103}$

They also noted that an aberrant expression of STn is an important event in high grade PanINs. ${ }^{103}$

In summary, the low grade PanINs show expression of MUC5AC and MUC6, and the high grade PanINs reveal overexpression of MUC1 and STn.

\section{Mucin expression in IPMN}

\section{1) Classification of IPMN combined with MUC1 and MUC2 expression}

In 1999, we classified IPMNs into three subtypes: IPMNs-villous dark cell type composed of dark columnar cells which form villous architecture morphologically sim- ilar to colonic villous adenoma (Upper column of Fig. 1, Left side of Fig. 12A), IPMNs-papillary clear cell type composed of clear columnar cells which form papillary architecture morphologically similar to gastric foveolar epithelium (Upper column of Fig. 1, and Left side of Fig. 12B), and IPMNs-compact cell type composed of piled-up cuboidal cells with eosinophilic cytoplasm, by the histological findings and mucin expression pattern. ${ }^{7,8}$ In 1999, we noted for the first time that the IPMNs-villous dark cell type showed MUC1-/MUC2+ pattern, whereas the IPMNs-papillary clear cell type showed MUC1-/MUC2pattern. ${ }^{8}$ A similar morphological observation was also reported by Fukushima et al., although they did not note mucin expression profiles. ${ }^{104}$ In 2002, we confirmed a difference of MUC2 expression between IPMNs-villous dark cell type and IPMNs-papillary clear cell type at the mRNA level by using in situ hybridization. ${ }^{6}$ In the same year, Adsay et al. reported two subtypes of IPMNs: intestinal type and pancreatobiliary type. ${ }^{105}$ They did not report mucin expression profiles yet, but the morphological characteristics of IPMNs-intestinal type are the same as IPMN-dark cell type in our classification. From the different patterns of MUC2 expression as well as the significant differences in the clinicopathological factors including the location, incidence of carcinoma, frequency of invasive proliferation, survival and so on between IPMNs-intestinal type and IPMNs-gastric type, we had stressed that IPMN-intestinal type with MUC2+ expression and IPMN-gastric type with MUC2-expression belong to different lineage of neoplasm. ${ }^{6,7}$

In the International Academy of Pathology held in Amsterdam in the autumn of 2002, the US and Europian pathologists commented that IPMNs-papillary clear cell type, which was described by Dr. Yonezawa's group,

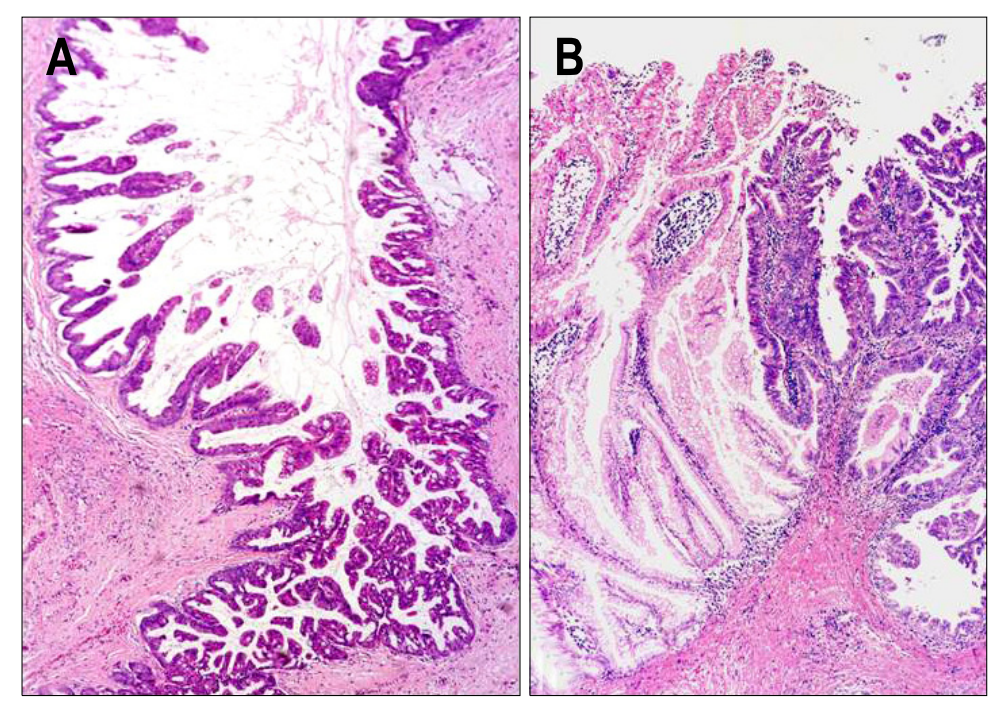

Fig. 12. Malignant transformation of intestinal-type IPMN (A) and gastric-type IPMN (B). In intestinal-type IPMN (A), adenomatous lesion (left side) is changed to carcinoma (right side). In gastric-type IPMN (B), adenomatous lesion (left side) is changed to carcinoma (right side), which was diagnosed as "pancreatobiliary-type IPMN" by US and European experts in pancreas pathology (Original magnification of microscopy images: A and $\mathrm{B}, \times 90)$. Reprinted from ref. 7 with permition. 
Japan, could not be observed in US and Europe, and then they named our "IPMNs-papillary clear cell type" as "Null type". However, in 2004, Adsay et al. again reported an article for IPMN classification with mucin expression profiles of MUC1 and MUC2, and classified into IPMNs-intestinal type, pancreatobiliary type and null type. ${ }^{11}$ In the article, they clearly described that their IPMN-intestinal type is "Yonezawa's dark cell type", and also noted that their IPMN-null type is similar to gastric foveolar epithelium or PanIN-1 epithelium and is the same type with our IPMN-clear cell type. ${ }^{11}$ In 2004 , an international consensus meeting for IPMN classification was held in Sendai, Japan. At that time, I expressed my opinion that it is the most important point that everybody recognize that there are two major subtypes in IPMNs, of which one is similar to intestinal villous adenoma with MUC1-/MUC2+ expression pattern, and another is similar to gastric foveolar epithelium with MUC1-/MUC2expression pattern, as we had already reported in our article in $1999,{ }^{8}$ but I did not adhere my nomenclature of "IPMN-dark cell type and IPMN-clear cell type". As the result, we had a consensus to use of the names of IPMNintestinal type for IPMN-dark cell type, and IPMN-gastric type for IPMN-clear cell type. ${ }^{10}$ We also wish to describe additional comments for nomenclature of IPMNs. We believe that the "classical IPMN" reported by Terris et al. ${ }^{106}$ is the same as IPMN-intestinal type, and their "hyperplastic type IPMN" may be the same as IPMN-gastric type.

The concept of distinction of IPMNs-subtypes, gastric type and intestinal type, is very important from the view point of clinical aspects including imaging diagnosis such as US, CT and MRI and so on. As described in our previous study, the IPMN-intestinal type with MUC2+ expression is located mainly in the main pancreatic duct, and shows high frequencies of malignant transformation (Fig. 12A) and invasive carcinoma (usually mucinous (colloid) carcinoma). ${ }^{6,7}$ In contrast, IPMN-gastric type with MUC2- expression is located usulally in the pancreatic branch duct, and rarely shows malignant transformation. ${ }^{6,7}$ These findings are well consistent with the clinical description in "International guideline for management of IPMN/MCN", ${ }^{107}$ in which IPMNs are classified into "IPMNs-main duct type" which are almost composed of IPMNs-intestinal type and "IPMNs-branch duct type" many of which are IPMNs-gastric type.

At the international consensus meeting for IPMN classification in 2004 mentioned above, a pathological diagnosis of the right side area in Figure 12B by experts for pancreas pathology was "IPMN-pancreatobiliary type". Thus, a case shown in Figure $12 \mathrm{~B}$ is a combined case of gastric type and pancreatobiliary type. From this finding, we suppose that the histological finding of severe atypia or carcinomatous change of IPMNs-gastric type may be the same as the pancreatobiliary type, which expressed glycosylated MUC1 (clone Ma695, Vector Laboratories, Burlingame, CA, USA). ${ }^{108}$

\section{2) Various glycoforms of MUC1 in IPMN}

Concerning the expression of different glycoforms of MUC1, there were distinct differences between PDACs and IPMNs (Table 1$).^{7}$ As shown in Table 1 , IPMNs-intestinal type showed no or rare expression of every MUC1 (MUC1/CORE, 0\%; MUC1/DF3, 0\%; MUC1/ MY.1E12, 0\%; MUC1/HMFG-1, 4\%). ${ }^{7}$ IPMNs-gastric type showed rare expression of underglycosylated MUC1 (MUC1/CORE, 6\%; MUC1/DF3, 3\%), but considerable high expression of sialylated or fully glycosylated MUC1 (MUC1/MY.1E12, 41\%; MUC1/HMFG-1, 69\%). ${ }^{7}$ Although there were distinct differences in the expression of underglycosylated MUC1 between PDACs and both IPMNs, we found that IPMNs-intestinal type develop invasive carcinomas where MUC1 was expressed frequently, ${ }^{6,109}$ whereas IPMNs-gastric type rarely develop carcinomas. ${ }^{6,7}$ As the results, survival of the patients with IPMNs-intestinal type was worse than that with IPMNs-gastric type. ${ }^{6,7}$

In addition, we demonstrated for the first time apparent differences in the expression of glycosylated MUC1 mucins (MUC1/MY.1E12 and MUC1/HMFG-1) between IPMNs-intestinal type and IPMNs-gastric type, ${ }^{7}$ as well as of MUC2 (Table 1). ${ }^{5,7}$ Rare expression of poorly glycosylated MUC1 mucins (MUC1/CORE and MUC1/DF3) was common to the two types of IPMNs. ${ }^{7}$ In contrast, sialylated MUC1 (MUC1/MY.1E12) and fully glycosylated MUC1 (MUC1/HMFG-1) were rarely expressed in IPMNs-intestinal type, whereas they were expressed in IPMNs-gastric type. ${ }^{7}$ We can not explain the reason of the exclusive expression of the glycosylated MUC1 mucins only in IPMNs-gastric type yet. However, the significantly different expression of the glycosylated MUC1 mucins between IPMNs-intestinal type and IPMNs-gastric type may support the concept that IPMNs-intestinal type and IPMNs-gastric type belong to different lineage of neoplasm.

Previous reports about in situ hybridization (ISH) for MUC1 gene expression reported that MUC1 transcript was expressed highly in PDACs but rarely in IPMNs, ${ }^{106,110}$ although the subtyptes of IPMNs were not noted in the reports. We also confirmed that PDACs express MUC1 transcript whereas IPMN-intestinal type did not. ${ }^{83}$ Those findings are consistent with high expression of all the glycoforms of MUC1 mucins in PDACs, and also with rare expression of them in IPMNs-intestinal type, reported in 
our study. ${ }^{7}$ However, expression of the glycosylated MUC1 in IPMNs-gastric type shows a discrepancy with rare expression of MUC1 transcript in IPMNs. Comparative large scale ISH study for MUC1 would clarify whether or not IPMN-gastric type express MUC1 transcript, and also whether or not the low expression of underglycosylated MUC1 (MUC1/ CORE and MUC1/ DF3) in IPMN-gastric type is owing to the masking of MUC1 core peptide by carbohydrate moieties detected by MAbs MY.1E12 and HMFG-1.

\section{3) MUC5AC and MUC6 in IPMN}

Gastric type mucins, MUC5AC and MUC6, as well as intestinal type mucin, MUC2 are gel forming mucins and they form of long polymers by end-to-end disulfate bonding, resulting in molecules with high viscosity in solution. ${ }^{111-113}$ MUC2, MUC5AC and MUC6 genes are located on the chromosome $11 \mathrm{p} 15.5$ region as a cluster of mucin gene complex. ${ }^{114}$

Since production of mucin is a peculiar characteristic of IPMN, we were interested in the expression profiles and disctribution patterns of MUC5AC and MUC6 as well as MUC2.

In the gastric mucins, MUC5AC showed very frequent expression in IPMNs-intestinal type (92\%) and IPMNsgastric type (100\%) (Table 1). ${ }^{7}$ On the other hand, MUC6, which is expressed in the gastric fundic or pyloric glands, showed variety of expression rates, i.e., relatively low in IPMNs-intestinal type $(37 \%)$ but high in IPMNsgastric type $(92 \%){ }^{7}$ High expression of MUC5AC in IPMNs was also reported by Luttges et al., ${ }^{69}$ although they did not comment about the subtypes of IPMNs.

Particularly in the papillary lesions of IPMNs-gastric type, there is a distinct difference in the expression sites between MUC5AC and MUC6, namely, MUC5AC was expressed frequently in the projected areas, whereas MUC6 was expressed mainly in the basal areas. ${ }^{7}$ In the normal gastric mucosa, MUC5AC is located mainly in the surface foveolar epithelium of the cardia, fundus and antrum of the stomach, whereas MUC6 is observed in the fundic and pyloric glands. ${ }^{115,116}$ The distribution patterns of MUC5AC and MUC6 in IPMNs-gastric type similar to those in the gastric mucosa may suggest a well differentiated state of the papillary structures of IPMNs-gastric type.

IPMNs-intestinal type imitate colorectal villous adenoma not only in the morphological appearance but also in the MUC2+ and MUC5AC+ expression. ${ }^{117}$ MUC2 expression is limited to IPMNs-intestinal type, whereas MUC5AC expression is observed not only in IPMNs-intestinal type but also in IPMNs-gastric type, as well as in
PDACs. These findings suggest different regulation mechanism between MUC2 gene and MUC5AC gene. Ho et al. reported a difference of methylation status between the promoter regions of MUC2 and MUC5AC. ${ }^{118}$ We also reported that MUC2 expression is regulated by an epigenetic mechanism, i.e., combination of histone $\mathrm{H} 3$ modification and DNA methylation in the 5' flanking region of the MUC2 promoter. ${ }^{41}$ MUC2 is expressed exculsively in IPMN-intestinal type, whereas MUC5AC is expressed in any pancreatic neoplastic lesions such as IPMN, PDAC and PanIN (even in the early grade such as PanIN-1). ${ }^{102}$ Relationship between the epigenetic regulation of MUC2 and MUC5AC genes in the two types of IPMNs and the expression pattern of MUC2 and MUC5AC mucins in them is an interesting future area of study.

\section{4) Summary of mucin expression in IPMNs}

Because of the differences in mucin expression pattern and potential for malignancy between the two types, we believe that IPMNs-intestinal type and IPMNs-gastric type may be reasonable to be classified into different entities. The classification of IPMNs into IPMNs-intestinal type and IPMNs-gastric type may be useful for the selection of the treatment method, such as conservative follow-up or surgical removal of the tumor, and also useful for the selection of the surgical methods, such as radical removal or partial resection of the tumor. We must watch the patients with IPMN-intestinal type more carefully. As we had reported in 2002, there are several combined cases of gastric type and intestinal type which show a clear border of between MUC2-area of gastric type and MUC2+ area of intestinal type. ${ }^{6}$ We are interested in whether or not there is a progression passway from gastric type to intestinal type or to pancreatobiliary type.

\section{Mucin expression in MCN}

Because MCNs are rare, there are only few reports of mucin expression in MCN. Hence, a expression profile of mucins in MCNs is not established yet. Lüttges et al. reported that expression of MUC1 is mostly absent in $\mathrm{MCN}$, except for one MUC1 positive case which is suspected to be invasion or undifferentiated carcinoma. ${ }^{69}$ In contrast, Terada et al. reported that MUC1/DF3 was expressed in $7(87.5 \%)$ of 8 cases of mucinous cystadenomas. ${ }^{119}$ No MUC2 experssion in MCN except for the goblet cells was reported in both studies. ${ }^{69,119}$

Zamboni et al. reported intestinal mucin markers CAR-5 (a marker of colorectal epithelium) and M3SI (a marker of small intestine goblet cells) were expressed more frequently in mucinous cystadenocarcinomas (38\%) than in mucinous cystic adenomas $(4 \%)$ or mucinous 
cystic borderline tumors (18\%). ${ }^{70}$ The higher malignancy potential of MCNs with intestinal type character seems to be similar to the higher malignancy potential of IPMN-intetstinal type compared with IPMN-gastric type.

MUC5AC expression rates in MCNs were different (37.5\% vs. $100 \%$ ) between two studies, ${ }^{69,119}$ Different antibody for MUC5AC in both studies explain the discrepancy.

In the study by Lüttges et al., MUC6 was expressed in only a few cells of about $30 \%$ cases of MCNs. ${ }^{69}$

In conclusion, MCNs seem to show no specific expression profile of mucins.

\section{Conclusion of mucin expression in PDACs and precursor lesions}

In conclusion, mucin expression profiles in PDACs and precursor lesions are as follows, (1) Increase in MUC1 expression correlated with increasing grades of PanINs, and high expression of all glycoforms of MUC1 was observed in PDACs; (2) Different expression pattern of MUC2 in major subtypes of IPMNs with different malignancy potential was observed: IPMNs-intestinal type with high malignancy potential showed MUC2+ expression and IPMNs-gastric type with low malignancy potential showed MUC2-expression; (3) Non-expression of MUC2 in any grades of PanINs was useful in differentiating PanIN from IPMN-intestinal type; (4) De novo expression of MUC4 appears to increase along with increasing dysplasia grade; (5) De novo high expression of MUC5AC occurs in all grades of PanINs, all types of IPMNs, MCNs and PDACs. MUC5AC is useful in detecting most pancreatic neoplastic lesions from the early stage but is not effective in differentiating the different histological types nor in discliminating the malignant pancreratic lesions.

\section{ACKNOWLEDGEMENTS}

We thank Ms. Mariko Tanaka and Ms. Eri Minamida for their secretarial assistance. This work was supported in part by a Grant-in-Aid from the Ministry of Education, Science, Sports, Culture and Technology, Japan (Scientific Research on Priority Areas 18014024 and 20014022, and Scientific Research (C) 20590345 to S. Yonezawa).

\section{REFERENCES}

1. Isaji S, Kawarada Y, Uemoto S. Classification of pancreatic cancer: comparison of Japanese and UICC classifications. Pancreas 2004;28:231-234.

2. Hruban RH, Adsay NV, Albores-Saavedra J, et al. Pancreatic intraepithelial neoplasia: a new nomenclature and classification system for pancreatic duct lesions. Am J Surg
Pathol 2001;25:579-586.

3. Klöppel G, Hruban RH, Longnecker DS, et al. Tumours of the exocrine pancreas. In: Hamilton SR, Aaltonen LA, eds. Pathology and genetics of tumours of the digestive system, World Health Organization Classification of Tumours. Lyon: IARC Press, 2000:219-240.

4. Hruban RJ, Pitman MB, Klimstra DS. Tumors of the pancreas. AFIP Atlas of tumor pathology, Fourth series. Washington DC: American Registry of Pathology, 2007.

5. Osako M, Yonezawa S, Siddiki B, et al. Immunohistochemical study of mucin carbohydrates and core proteins in human pancreatic tumors. Cancer 1993;71:2191-2199.

6. Nakamura A, Horinouchi $M$, Goto $M$, et al. New classification of pancreatic intraductal papillary-mucinous tumour by mucin expression: its relationship with potential for malignancy. J Pathol 2002;197:201-210.

7. Horinouchi M, Nagata K, Nakamura A, et al. Expression of different glycoforms of membrane mucin (MUC1) and secretory mucin (MUC2, MUC5AC and MUC6) in pancreatic neoplasms. Acta Histochem Cytochem 2003;36:443453.

8. Yonezawa S, Horinouchi M, Osako M, et al. Gene expression of gastric type mucin (MUC5AC) in pancreatic tumors: its relationship with the biological behavior of the tumor. Pathol Int 1999;49:45-54.

9. Adsay NV, Adair CF, Heffess CS, Klimstra DS. Intraductal oncocytic papillary neoplasms of the pancreas. Am J Surg Pathol 1996;20:980-994.

10. Furukawa T, Klöppel G, Volkan Adsay N, et al. Classification of types of intraductal papillary-mucinous neoplasm of the pancreas: a consensus study. Virchows Arch 2005;447: 794-799.

11. Adsay NV, Merati K, Basturk O, et al. Pathologically and biologically distinct types of epithelium in intraductal papillary mucinous neoplasms: delineation of an "intestinal" pathway of carcinogenesis in the pancreas. Am J Surg Pathol 2004;28:839-848.

12. Almoguera C, Shibata D, Forrester K, et al. Most human carcinomas of the exocrine pancreas contain mutant c-K-ras genes. Cell 1988;53:549-554.

13. Smit VT, Boot AJ, Smits AM, Fleuren GJ, Cornelisse CJ, Bos JL. KRAS codon 12 mutations occur very frequently in pancreatic adenocarcinomas. Nucleic Acids Res 1988;16: 7773-7782.

14. Hruban RH, Wilentz RE, Kern SE. Genetic progression in the pancreatic ducts. Am J Pathol 2000;156:1821-1825.

15. Bos JL. ras oncogenes in human cancer: a review. Cancer Res 1989;49:4682-4689.

16. Pellegata NS, Sessa F, Renault B, et al. K-ras and p53 gene mutations in pancreatic cancer: ductal and nonductal tumors progress through different genetic lesions. Cancer Res 1994;54:1556-1560.

17. Yanagisawa A, Ohtake K, Ohashi K, et al. Frequent c-Kiras oncogene activation in mucous cell hyperplasias of pancreas suffering from chronic inflammation. Cancer Res 1993;53:953-956.

18. Caldas C, Hahn SA, Hruban RH, Redston MS, Yeo CJ, Kern SE. Detection of K-ras mutations in the stool of patients with pancreatic adenocarcinoma and pancreatic ductal hyperplasia. Cancer Res 1994;54:3568-3573.

19. Day JD, Digiuseppe JA, Yeo C, et al. Immunohistochemical 
evaluation of HER-2/neu expression in pancreatic adenocarcinoma and pancreatic intraepithelial neoplasms. Hum Pathol 1996;27:119-124.

20. Rozenblum E, Schutte M, Goggins M, et al. Tumor-suppressive pathways in pancreatic carcinoma. Cancer Res 1997;57:1731-1734.

21. Wilentz RE, Geradts J, Maynard R, et al. Inactivation of the p16 (INK4A) tumor-suppressor gene in pancreatic duct lesions: loss of intranuclear expression. Cancer Res 1998; 58:4740-4744.

22. DiGiuseppe JA, Hruban RH, Goodman SN, et al. Overexpression of $\mathrm{p} 53$ protein in adenocarcinoma of the pancreas. Am J Clin Pathol 1994;101:684-688.

23. Hahn SA, Schutte M, Hoque AT, et al. DPC4, a candidate tumor suppressor gene at human chromosome 18q21.1. Science 1996;271:350-353.

24. Wilentz RE, Su GH, Dai JL, et al. Immunohistochemical labeling for dpc4 mirrors genetic status in pancreatic adenocarcinomas: a new marker of DPC4 inactivation. Am J Pathol 2000;156:37-43.

25. Wilentz RE, Iacobuzio-Donahue CA, Argani P, et al. Loss of expression of Dpc4 in pancreatic intraepithelial neoplasia: evidence that DPC4 inactivation occurs late in neoplastic progression. Cancer Res 2000;60:2002-2006.

26. McCarthy DM, Brat DJ, Wilentz RE, et al. Pancreatic intraepithelial neoplasia and infiltrating adenocarcinoma: analysis of progression and recurrence by DPC4 immunohistochemical labeling. Hum Pathol 2001;32:638-642.

27. Goggins M, Hruban RH, Kern SE. BRCA2 is inactivated late in the development of pancreatic intraepithelial neoplasia: evidence and implications. Am J Pathol 2000;156: 1767-1771.

28. Yamano M, Fujii H, Takagaki T, Kadowaki N, Watanabe $\mathrm{H}$, Shirai T. Genetic progression and divergence in pancreatic carcinoma. Am J Pathol 2000;156:2123-2133.

29. Kimura $M$, Abe $T$, Sunamura $M$, Matsuno S, Horii A. Detailed deletion mapping on chromosome arm 12q in human pancreatic adenocarcinoma: identification of a I-cM region of common allelic loss. Genes Chromosomes Cancer 1996;17:88-93.

30. Yatsuoka T, Sunamura M, Furukawa T, et al. Association of poor prognosis with loss of $12 \mathrm{q}, 17 \mathrm{p}$, and 18q, and concordant loss of $6 q / 17 p$ and $12 q / 18 q$ in human pancreatic ductal adenocarcinoma. Am J Gastroenterol 2000;95: 2080-2085.

31. Fukushige $S$, Waldman FM, Kimura $M$, et al. Frequent gain of copy number on the long arm of chromosome 20 in human pancreatic adenocarcinoma. Genes Chromosomes Cancer 1997;19:161-169.

32. Fukushige S, Furukawa T, Satoh $\mathrm{K}$, et al. Loss of chromosome $18 \mathrm{q}$ is an early event in pancreatic ductal tumorigenesis. Cancer Res 1998;58:4222-4226.

33. Matsubayashi H, Sato N, Fukushima N, et al. Methylation of cyclin D2 is observed frequently in pancreatic cancer but is also an age-related phenomenon in gastrointestinal tissues. Clin Cancer Res 2003;9:1446-1452.

34. Sato N, Fukushima N, Maitra A, et al. Discovery of novel targets for aberrant methylation in pancreatic carcinoma using high-throughput microarrays. Cancer Res 2003;63: 3735-3742.

35. Ueki $\mathrm{T}$, Toyota $\mathrm{M}$, Skinner $\mathrm{H}$, et al. Identification and characterization of differentially methylated $\mathrm{CpG}$ islands in pancreatic carcinoma. Cancer Res 2001;61:8540-8546.

36. Ueki T, Toyota M, Sohn $\mathrm{T}$, et al. Hypermethylation of multiple genes in pancreatic adenocarcinoma. Cancer Res 2000;60:1835-1839.

37. Fukushima N, Sato N, Ueki T, et al. Aberrant methylation of preproenkephalin and p16 genes in pancreatic intraepithelial neoplasia and pancreatic ductal adenocarcinoma. Am J Pathol 2002;160:1573-1581.

38. Fukushima N, Walter KM, Uek T, et al. Diagnosing pancreatic cancer using methylation specific PCR analysis of pancreatic juice. Cancer Biol Ther 2003;2:78-83.

39. Yamada N, Nishida Y, Tsutsumida $\mathrm{H}$, et al. MUC1 expression is regulated by DNA methylation and histone $\mathrm{H} 3$ lysine 9 modification in cancer cells. Cancer Res 2008;68: 2708-2716.

40. Hamada T, Goto M, Tsutsumida H, et al. Mapping of the methylation pattern of the MUC2 promoter in pancreatic cancer cell lines, using bisulfite genomic sequencing. Cancer Lett 2005;227:175-184.

41. Yamada N, Hamada T, Goto M, et al. MUC2 expression is regulated by histone $\mathrm{H} 3$ modification and DNA methylation in pancreatic cancer. Int J Cancer 2006;119:18501857.

42. Logsdon CD, Simeone DM, Binkley C, et al. Molecular profiling of pancreatic adenocarcinoma and chronic pancreatitis identifies multiple genes differentially regulated in pancreatic cancer. Cancer Res 2003;63:2649-2657.

43. Flejou JF, Boulange B, Bernades P, Belghiti J, Henin D. p53 protein expression and DNA ploidy in cystic tumors of the pancreas. Pancreas 1996;13:247-252.

44. Sessa F, Solcia E, Capella C, et al. Intraductal papillary-mucinous tumours represent a distinct group of pancreatic neoplasms: an investigation of tumour cell differentiation and K-ras, p53 and c-erbB-2 abnormalities in 26 patients. Virchows Arch 1994;425:357-367.

45. Hoshi T, Imai M, Ogawa K. Frequent K-ras mutations and absence of p53 mutations in mucin-producing tumors of the pancreas. J Surg Oncol 1994;55:84-91.

46. Yoshizawa K, Nagai H, Sakurai S, et al. Clonality and K-ras mutation analyses of epithelia in intraductal papillary mucinous tumor and mucinous cystic tumor of the pancreas. Virchows Arch 2002;441:437-443.

47. Z'Graggen K, Rivera JA, Compton CC, et al. Prevalence of activating K-ras mutations in the evolutionary stages of neoplasia in intraductal papillary mucinous tumors of the pancreas. Ann Surg 1997;226:491-498; discussion 498-500.

48. Moore PS, Orlandini S, Zamboni G, et al. Pancreatic tumours: molecular pathways implicated in ductal cancer are involved in ampullary but not in exocrine nonductal or endocrine tumorigenesis. Br J Cancer 2001;84:253-262.

49. Fujii $\mathrm{H}$, Inagaki $\mathrm{M}$, Kasai $\mathrm{S}$, et al. Genetic progression and heterogeneity in intraductal papillary-mucinous neoplasms of the pancreas. Am J Pathol 1997;151:1447-1454.

50. Biankin AV, Biankin SA, Kench JG, et al. Aberrant p16 (INK4A) and DPC4/Smad4 expression in intraductal papillary mucinous tumours of the pancreas is associated with invasive ductal adenocarcinoma. Gut 2002;50:861-868.

51. Nakata B, Yashiro M, Nishioka N, et al. Very low incidence of microsatellite instability in intraductal papillary-mucinous neoplasm of the pancreas. Int $\mathrm{J}$ Cancer 
2002;102:655-659.

52. Sasaki S, Yamamoto $H$, Kaneto $H$, et al. Differential roles of alterations of p53, p16, and SMAD4 expression in the progression of intraductal papillary-mucinous tumors of the pancreas. Oncol Rep 2003;10:21-25.

53. Satoh K, Shimosegawa T, Moriizumi S, Koizumi M, Toyota T. K-ras mutation and p53 protein accumulation in intraductal mucin-hypersecreting neoplasms of the pancreas. Pancreas 1996;12:362-368.

54. Iacobuzio-Donahue CA, Klimstra DS, Adsay NV, et al. Dpc-4 protein is expressed in virtually all human intraductal papillary mucinous neoplasms of the pancreas: comparison with conventional ductal adenocarcinomas. Am J Pathol 2000;157:755-761.

55. Su GH, Hruban RH, Bansal RK, et al. Germline and somatic mutations of the STK11/LKB1 Peutz-Jeghers gene in pancreatic and biliary cancers. Am J Pathol 1999;154: 1835-1840.

56. Sato N, Rosty C, Jansen M, et al. STK11/LKB1 PeutzJeghers gene inactivation in intraductal papillary-mucinous neoplasms of the pancreas. Am J Pathol 2001;159:20172022.

57. Maire F, Hammel P, Terris B, et al. Intraductal papillary and mucinous pancreatic tumour: a new extracolonic tumour in familial adenomatous polyposis. Gut 2002;51: 446-449.

58. Chetty R, Serra S, Salahshor S, et al. Expression of Wnt-signaling pathway proteins in intraductal papillary mucinous neoplasms of the pancreas: a tissue microarray analysis. Hum Pathol 2006;37:212-217.

59. Wada K. p16 and p53 gene alterations and accumulations in the malignant evolution of intraductal papillary-mucinous tumors of the pancreas. J Hepatobiliary Pancreat Surg 2002;9:76-85.

60. Sato N, Ueki T, Fukushima N, et al. Aberrant methylation of $\mathrm{CpG}$ islands in intraductal papillary mucinous neoplasms of the pancreas. Gastroenterology 2002;123:365372.

61. Fukushima N, Sato N, Sahin F, Su GH, Hruban RH, Goggins M. Aberrant methylation of suppressor of cytokine signalling-1 (SOCS-1) gene in pancreatic ductal neoplasms. Br J Cancer 2003;89:338-343.

62. House MG, Guo M, Iacobuzio-Donahue C, Herman JG. Molecular progression of promoter methylation in intraductal papillary mucinous neoplasms (IPMN) of the pancreas. Carcinogenesis 2003;24:193-198.

63. Sato N, Fukushima N, Maitra A, et al. Gene expression profiling identifies genes associated with invasive intraductal papillary mucinous neoplasms of the pancreas. Am J Pathol 2004;164:903-914.

64. Terris B, Blaveri E, Crnogorac-Jurcevic T, et al. Characterization of gene expression profiles in intraductal papillary-mucinous tumors of the pancreas. Am J Pathol 2002; 160:1745-1754.

65. Bartsch D, Bastian D, Barth P, et al. K-ras oncogene mutations indicate malignancy in cystic tumors of the pancreas. Ann Surg 1998;228:79-86.

66. Brenin DR, Talamonti MS, Yang EY, et al. Cystic neoplasms of the pancreas. A clinicopathologic study, including DNA flow cytometry. Arch Surg 1995;130:1048-1054.

67. Jimenez RE, Warshaw AL, Z'Graggen $K$, et al. Sequential accumulation of K-ras mutations and p53 overexpression in the progression of pancreatic mucinous cystic neoplasms to malignancy. Ann Surg 1999;230:501-509; discussion 509-511.

68. Kim SG, Wu TT, Lee JH, et al. Comparison of epigenetic and genetic alterations in mucinous cystic neoplasm and serous microcystic adenoma of pancreas. Mod Pathol 2003; 16:1086-1094.

69. Luttges J, Feyerabend B, Buchelt T, Pacena M, Kloppel G. The mucin profile of noninvasive and invasive mucinous cystic neoplasms of the pancreas. Am J Surg Pathol 2002; 26:466-471.

70. Zamboni G, Scarpa A, Bogina G, et al. Mucinous cystic tumors of the pancreas: clinicopathological features, prognosis, and relationship to other mucinous cystic tumors. Am J Surg Pathol 1999;23:410-422.

71. Iacobuzio-Donahue CA, Wilentz RE, Argani P, et al. Dpc4 protein in mucinous cystic neoplasms of the pancreas: frequent loss of expression in invasive carcinomas suggests a role in genetic progression. Am J Surg Pathol 2000;24: 1544-1548.

72. Hollingsworth MA, Swanson BJ. Mucins in cancer: protection and control of the cell surface. Nat Rev Cancer 2004;4:45-60.

73. Lehmann JM, Riethmuller G, Johnson JP. MUC18, a marker of tumor progression in human melanoma, shows sequence similarity to the neural cell adhesion molecules of the immunoglobulin superfamily. Proc Natl Acad Sci U S A 1989;86:9891-9895.

74. Chen Y, Zhao YH, Kalaslavadi TB, et al. Genome-wide search and identification of a novel gel-forming mucin MUC19/MUC19 in glandular tissues. Am J Respir Cell Mol Biol 2004;30:155-165.

75. Higuchi T, Orita T, Nakanishi S, et al. Molecular cloning, genomic structure, and expression analysis of MUC20, a novel mucin protein, up-regulated in injured kidney. J Biol Chem 2004;279:1968-1979.

76. Moniaux N, Escande F, Porchet N, Aubert JP, Batra SK. Structural organization and classification of the human mucin genes. Front Biosci 2001;6:D1192-1206.

77. Kitamura H, Yonezawa S, Tanaka S, Kim YS, Sato E. Expression of mucin carbohydrates and core proteins in carcinomas of the ampulla of Vater: their relationship to prognosis. Jpn J Cancer Res 1996;87:631-640.

78. Utsunomiya T, Yonezawa S, Sakamoto H, et al. Expression of MUC1 and MUC2 mucins in gastric carcinomas: its relationship with the prognosis of the patients. Clin Cancer Res 1998;4:2605-2614.

79. Sagara M, Yonezawa S, Nagata $\mathrm{K}$, et al. Expression of mucin 1 (MUC1) in esophageal squamous-cell carcinoma: its relationship with prognosis. Int J Cancer 1999;84:251-257.

80. Takao S, Uchikura K, Yonezawa S, Shinchi H, Aikou T. Mucin core protein expression in extrahepatic bile duct carcinoma is associated with metastases to the liver and poor prognosis. Cancer 1999;86:1966-1975.

81. Higashi M, Yonezawa S, Ho JJ, et al. Expression of MUC1 and MUC2 mucin antigens in intrahepatic bile duct tumors: its relationship with a new morphological classification of cholangiocarcinoma. Hepatology 1999;30:13471355.

82. Tamada S, Goto M, Nomoto M, et al. Expression of MUC1 
and MUC2 mucins in extrahepatic bile duct carcinomas: its relationship with tumor progression and prognosis. Pathol Int 2002;52:713-723.

83. Yonezawa S, Nakamura A, Horinouchi M, Sato E. The expression of several types of mucin is related to the biological behavior of pancreatic neoplasms. J Hepatobiliary Pancreat Surg 2002;9:328-341.

84. Hinoda $Y$, Ikematsu Y, Horinochi M, et al. Increased expression of MUC1 in advanced pancreatic cancer. J Gastroenterol 2003;38:1162-1166.

85. Tsutsumida H, Goto M, Kitajima S, Kubota I, Hirotsu Y, Yonezawa S. Combined status of MUC1 mucin and surfactant apoprotein A expression can predict the outcome of patients with small-size lung adenocarcinoma. Histopathology 2004;44:147-155.

86. Hamada T, Matsukita S, Goto M, et al. Mucin expression in pleomorphic adenoma of salivary gland: a potential role for MUC1 as a marker to predict recurrence. J Clin Pathol 2004;57:813-821.

87. Yonezawa S, Sato E. Expression of mucin antigens in human cancers and its relationship with malignancy potential. Pathol Int 1997;47:813-830.

88. Yamashita K, Yonezawa S, Tanaka S, et al. Immunohistochemical study of mucin carbohydrates and core proteins in hepatolithiasis and cholangiocarcinoma. Int J Cancer 1993;55:82-91.

89. Yonezawa S, Nomoto M, Matsukita S, et al. Expression of MUC2 gene product in mucinous carcinoma of the breast: Comparison with invasive ductal carcinoma. Acta Histochem Cytochem 1995;28:239-246.

90. Yonezawa S, Sueyoshi K, Nomoto M, et al. MUC2 gene expression is found in noninvasive tumors but not in invasive tumors of the pancreas and liver: its close relationship with prognosis of the patients. Hum Pathol 1997;28:344-352.

91. Matsukita S, Nomoto M, Kitajima S, et al. Expression of mucins (MUC1, MUC2, MUC5AC and MUC6) in mucinous carcinoma of the breast: comparison with invasive ductal carcinoma. Histopathology 2003;42:26-36.

92. Yonezawa S, Nakamura T, Tanaka S, Sato E. Glycoconjugate with Ulex europaeus agglutinin-I-binding sites in normal mucosa, adenoma, and carcinoma of the human large bowel. J Natl Cancer Inst 1982;69:777-785.

93. Sato E, Maruta K, Yonezawa S, Nakamura T. Blood group $\mathrm{H}(\mathrm{O})$ antigen in normal, dysplastic and carcinomatous esophageal epithelium. Gann 1984;75:223-229.

94. Shimizu T, Yonezawa S, Tanaka S, Sato E. Expression of Lewis X-related antigens in adenocarcinomas of lung. Histopathology 1993;22:549-555.

95. Yonezawa S, Tachikawa T, Shin S, Sato E. Sialosyl-Tn antigen. Its distribution in normal human tissues and expression in adenocarcinomas. Am J Clin Pathol 1992;98: 167-174.

96. Yonezawa S, Byrd JC, Dahiya R, et al. Differential mucin gene expression in human pancreatic and colon cancer cells. Biochem J 1991;276(Pt3):599-605.

97. Burchell J, Gendler S, Taylor-Papadimitriou J, et al. Development and characterization of breast cancer reactive monoclonal antibodies directed to the core protein of the human milk mucin. Cancer Res 1987;47:5476-5482.

98. Nakamori S, Ota DM, Cleary KR, Shirotani K, Irimura T. MUC1 mucin expression as a marker of progression and metastasis of human colorectal carcinoma. Gastroenterol- ogy $1994 ; 106: 353-361$.

99. Saitou M, Goto M, Horinouchi M, et al. MUC4 expression is a novel prognostic factor in patients with invasive ductal carcinoma of the pancreas. J Clin Pathol 2005;58:845-852.

100. Swartz MJ, Batra SK, Varshney GC, et al. MUC4 expression increases progressively in pancreatic intraepithelial neoplasia. Am J Clin Pathol 2002;117:791-796.

101. Park HU, Kim JW, Kim GE, et al. Aberrant expression of MUC3 and MUC4 membrane-associated mucins and sialyl $\mathrm{Le}(\mathrm{x})$ antigen in pancreatic intraepithelial neoplasia. Pancreas 2003;26:e48-54.

102. Nagata K. Analysis of mucins and CD10 expression in pancreatic intraductal neoplasia. Kagoshimadaigaku Igakuzashi 2005;57:7-17 (in Japanese with English abstract).

103. Kim GE, Bae HI, Park HU, et al. Aberrant expression of MUC5AC and MUC6 gastric mucins and sialyl Tn antigen in intraepithelial neoplasms of the pancreas. Gastroenterology 2002;123:1052-1060.

104. Fukushima N, Mukai K, Kanai Y, et al. Intraductal papillary tumors and mucinous cystic tumors of the pancreas: clinicopathologic study of 38 cases. Hum Pathol 1997; 28:1010-1017.

105. Adsay NV, Conlon KC, Zee SY, Brennan MF, Klimstra DS. Intraductal papillary-mucinous neoplasms of the pancreas: an analysis of in situ and invasive carcinomas in 28 patients. Cancer 2002;94:62-77.

106. Terris B, Dubois S, Buisine MP, et al. Mucin gene expression in intraductal papillary-mucinous pancreatic tumours and related lesions. J Pathol 2002;197:632-637.

107. Tanaka M, Chari S, Adsay V, et al. International consensus guidelines for management of intraductal papillary mucinous neoplasms and mucinous cystic neoplasms of the pancreas. Pancreatology 2006;6:17-32.

108. Adsay NV, Merati K, Andea A, et al. The dichotomy in the preinvasive neoplasia to invasive carcinoma sequence in the pancreas: differential expression of MUC1 and MUC2 supports the existence of two separate pathways of carcinogenesis. Mod Pathol 2002;15:1087-1095.

109. Yonezawa S, Taira M, Osako M, et al. MUC-1 mucin expression in invasive areas of intraductal papillary mucinous tumors of the pancreas. Pathol Int 1998;48:319-322.

110. Balague C, Audie JP, Porchet N, Real FX. In situ hybridization shows distinct patterns of mucin gene expression in normal, benign, and malignant pancreas tissues. Gastroenterology 1995;109:953-964.

111. Gum JR Jr. Mucin genes and the proteins they encode: structure, diversity, and regulation. Am J Respir Cell Mol Biol 1992;7:557-564.

112. Gum JR Jr, Hicks JW, Toribara NW, Siddiki B, Kim YS. Molecular cloning of human intestinal mucin (MUC2) cDNA. Identification of the amino terminus and overall sequence similarity to prepro-von Willebrand factor. J Biol Chem 1994;269:2440-2446.

113. Kim YS, Gum JR Jr. Diversity of mucin genes, structure, function, and expression. Gastroenterology 1995;109:9991001.

114. Pigny P, Guyonnet-Duperat V, Hill AS, et al. Human mucin genes assigned to $11 \mathrm{p} 15.5$ : identification and organization of a cluster of genes. Genomics 1996;38:340-352.

115. De Bolos C, Garrido M, Real FX. MUC6 apomucin shows 
a distinct normal tissue distribution that correlates with Lewis antigen expression in the human stomach. Gastroenterology 1995;109:723-734.

116. Ho SB, Roberton AM, Shekels LL, Lyftogt CT, Niehans GA, Toribara NW. Expression cloning of gastric mucin complementary DNA and localization of mucin gene expression. Gastroenterology 1995;109:735-747.

117. Buisine MP, Janin A, Maunoury V, et al. Aberrant expression of a human mucin gene (MUC5AC) in rec- tosigmoid villous adenoma. Gastroenterology 1996;110: 84-91.

118. Ho JJ, Han SW, Pan PL, Deng G, Kuan SF, Kim YS. Methylation status of promoters and expression of MUC2 and MUC5AC mucins in pancreatic cancer cells. Int J Oncol 2003;22:273-279.

119. Terada T, Ohta T, Sasaki M, Nakanuma Y, Kim YS. Expression of MUC apomucins in normal pancreas and pancreatic tumours. J Pathol 1996;180:160-165. 